\title{
Recent Studies in Turbine Blade Cooling*
}

\author{
Je-Chin Han \\ Department of Mechanical Engineering, Texas A\&M University, College Station, Texas, USA
}

Gas turbines are used extensively for aircraft propulsion, land-based power generation, and industrial applications. Developments in turbine cooling technology play a critical role in increasing the thermal efficiency and power output of advanced gas turbines. Gas turbine blades are cooled internally by passing the coolant through several rib-enhanced serpentine passages to remove heat conducted from the outside surface. External cooling of turbine blades by film cooling is achieved by injecting relatively cooler air from the internal coolant passages out of the blade surface in order to form a protective layer between the blade surface and hot gas-path flow. For internal cooling, this presentation focuses on the effect of rotation on rotor blade coolant passage heat transfer with rib turbulators and impinging jets. The computational flow and heat transfer results are also presented and compared to experimental data using the RANS method with various turbulence models such as $k-\varepsilon$, and second-moment closure models. This presentation includes unsteady high free-stream turbulence effects on film cooling performance with a discussion of detailed heat transfer coefficient and film-cooling effectiveness distributions for standard and shaped film-hole geometry using the newly developed transient liquid crystal image method.

Keywords Blade internal cooling, Rotational effect, Film cooling, Unsteady effect

\section{INTRODUCTION}

Advanced gas turbine engines operate at high temperatures (1200-1500C) to improve thermal efficiency and power output.

Received 13 February 2002; accepted 29 October 2002.

*This paper was presented at the 9th International Symposium on Rotating Machinery.

This article was prepared under a project sponsored by United Technologies/Pratt \& Whitney. The Pratt \& Whitney project manager was Mr. Friedrich O. Soechting. Their support is greatly appreciated.

Address correspondence to Je-Chin Han, Turbine Heat Transfer Laboratory, Department of Mechanical Engineering, Texas A\&M University, College Station, TX 77843-3123. E-mail: jchan@mengr. tamu.edu
As the turbine inlet temperature increases, the heat transferred to the turbine blade also increases. The level and variation in the temperature within the blade material, which cause thermal stresses, must be limited to achieve reasonable durability goals. The operating temperatures are far above the permissible metal temperatures. Therefore, there is a critical need to cool the blades for safe operation. The blades are cooled with extracted air from the compressor of the engine. Since this extraction incurs a penalty on the thermal efficiency and power output of the engine, it is important to understand and optimize the cooling technology for a given turbine blade geometry under engine operating conditions. Gas turbine cooling technology is complex and varies between engine manufacturers. Figure 1 shows the common cooling technology with three major internal cooling zones in a turbine blade with strategic film cooling in the leading edge, pressure and suction surfaces, and blade tip region. The leading edge is cooled by jet impingement with film cooling, the middle portion is cooled by serpentine rib-roughened passages with local film cooling, and the trailing edge is cooled by pin fins with trailing edge injection. This article focuses on the rotational effects on the turbine blade internal cooling passage heat transfer and the unsteady high free-stream turbulence effects on the turbine blade film cooling performance with standard and shaped film-hole geometry. Interested readers are referred to several recent publications that address state-of-the-art reviews of turbine blade cooling and heat transfer. These include rotational effect on the turbine blade coolant passage heat transfer by Dutta and Han (1998), recent developments in turbine blade film cooling by Han and Ekkad (2001), and recent developments in turbine blade internal cooling by Han and Dutta (2001). A recent book focusing entirely on the range of gas turbine heat transfer issues and the associated cooling technology is available by Han et al. (2000). A symposium volume dealt with heat transfer in gas turbine systems is recently edited by Goldstein (2001). A detailed review of convective heat transfer and aerodynamics in axial flow turbines is now available by Dunn (2001).

\section{COOLANT PASSAGE HEAT TRANSFER WITH RIB TURBULATORS}

In advanced gas turbine blades, rib turbulators are often cast on two opposite walls of internal coolant passages to augment 

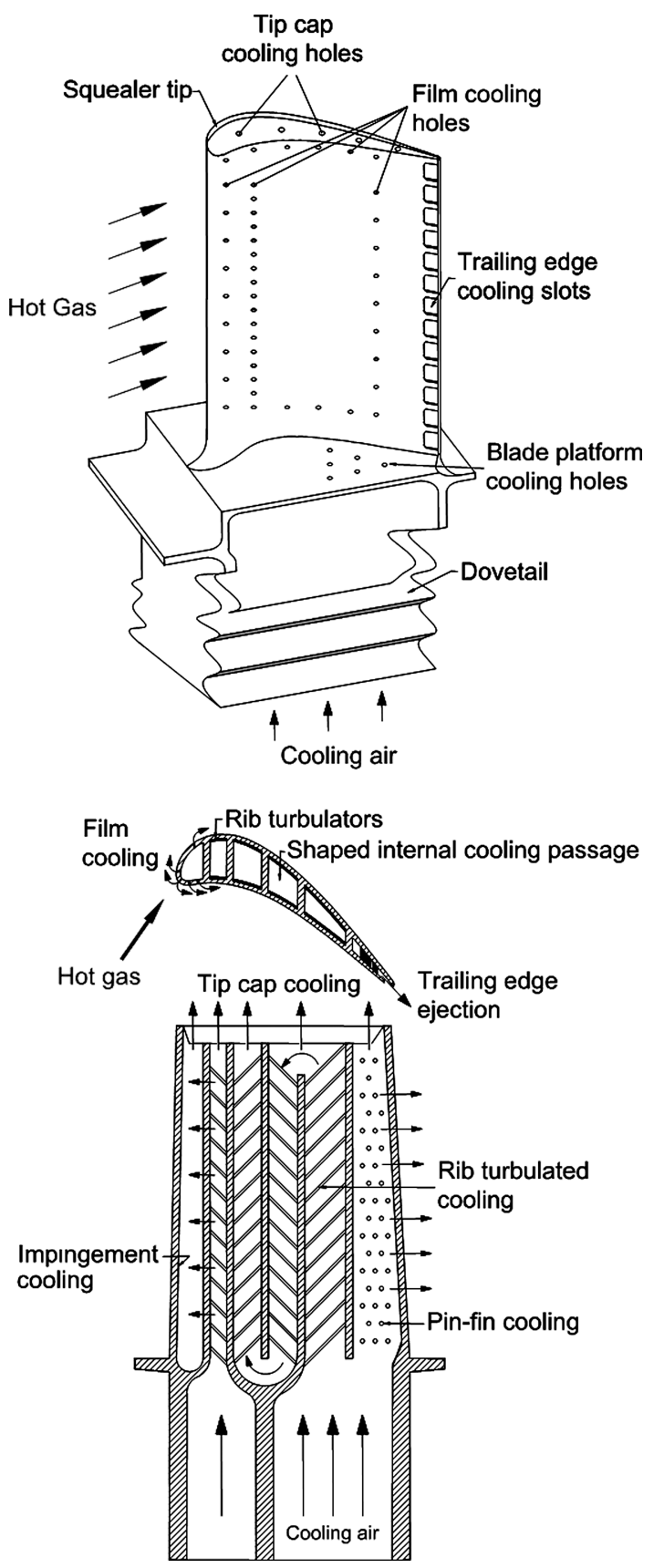

FIGURE 1

The schematic of a modern gas turbine blade with common cooling techniques.

heat transfer. The internal coolant passages are mostly modeled as short, square or rectangular channels with various aspect ratios. The heat transfer augmentation in rectangular coolant passages with rib turbulators primarily depends upon the rib turbulators' geometry, such as rib size, shape, distribution, flowattack-angle, and the flow Reynolds number. Rib turbulators disturb only the near-wall flow for heat transfer enhancement. Therefore, the pressure drop penalty caused by rib turbulators

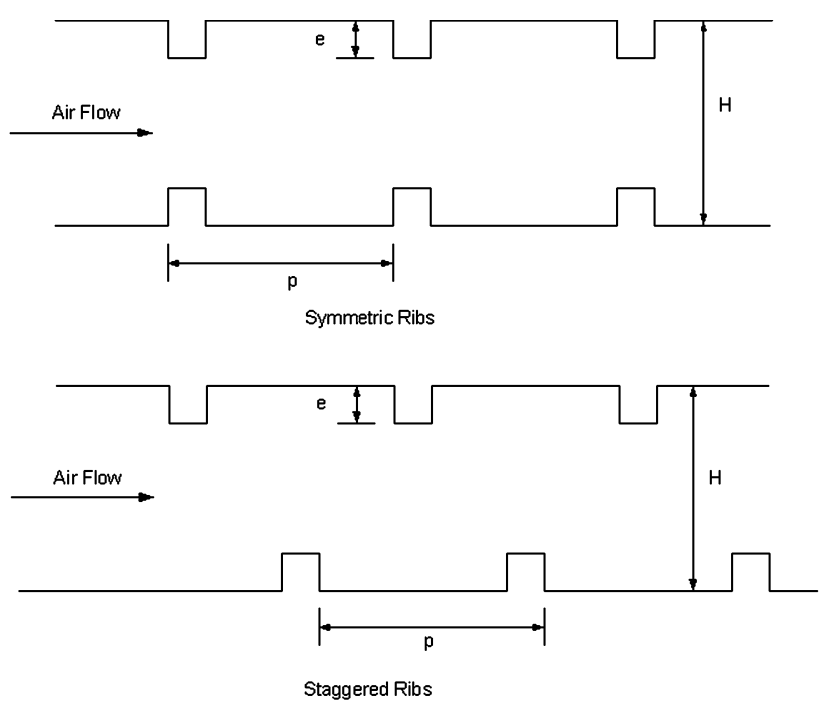

(a)

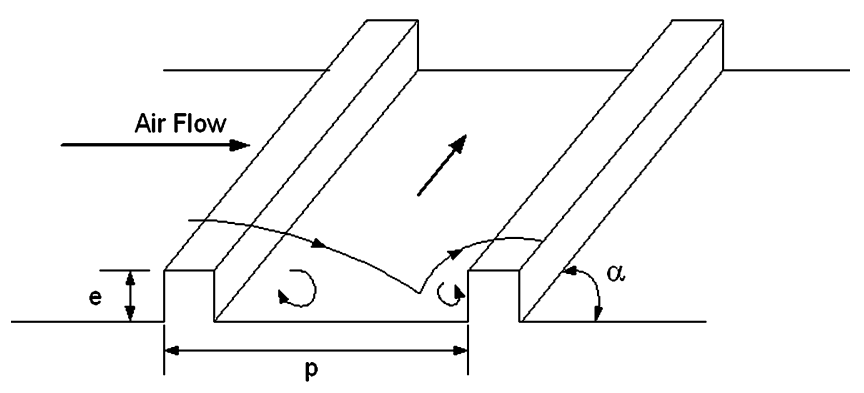

(b)

FIGURE 2

(a) Symmetric and staggered rib arrangements in opposite walls of cooling channel. (b) Schematic of flow separation from ribs and secondary flow between angled ribs in a rib-turbulated cooling channel.

is affordable for the blade internal cooling designs. There have been many basic studies by Han et al. (1978, 1985, 1988, 1989, 1991) and Han (1988) to understand the heat transfer augmentation versus the pressure drop penalty by the flow separation caused by rib-turbulators. Figure 2a shows symmetric (parallel) and staggered rib arrangements in opposite walls of a cooling channel. Figure $2 \mathrm{~b}$ shows schematics of flow separations from repeated ribs reattach on the floors between ribs thus increasing the heat transfer coefficients of the ribs and the floors. The heat transfer coefficients can be further enhanced by casting the ribs with an angle to the coolant flow, which causes a rib-induced secondary flow moving in the rib angle direction. The Reynolds numbers based on coolant channel hydraulic diameter vary from 10,000 to 80,000 . However, the Reynolds numbers can be up to 500,000 for the coolant passages in large power generation turbine blades. In general, the repeated ribs that used for coolant 
passages with a channel aspect ratio varying from $1 / 4$ (near blade leading edge) to 4 (near blade trailing edge), are nearly square in cross section with a typical relative rib height of 5-10\% of the coolant channel hydraulic diameter, a rib spacing-to-height ratio varying from 5-15, and a rib flow-attack-angle around 30-60 .

In general, smaller rib height is more efficient for higher Reynolds number flows, and the heat transfer enhancement decreases but pressure drop penalty increases with the Reynolds number. For example, the heat transfer can be enhanced about 3 times with 5 times pressure drop penalty in a square channel with typical rib geometry (6\% rib height-to-channel hydraulic diameter ratio, 10 rib spacing-to-height ratio, and $45^{\circ}$ rib flowattack-angle) at a Reynolds number around 30,000. Several studies by Han et al. $(1992,1993,1998)$ show that the V-shaped and Delta-shaped ribs provide better heat transfer performance than the typical angled rib geometry for a given pressure drop penalty. Figure 3 shows conceptual view of secondary flow vortices induced by angled ribs and V-shaped ribs. However, larger rib height-to-channel hydraulic diameter ratio can be used to generate a little more heat transfer enhancement if the pressure drop penalty is not a main concern in some highly demanding cooling designs. Also, the closer (or wider) rib spacing has reduced heat transfer enhancement and pressure drop penalty. Therefore, the closer (or wider) rib spacing can be used to get enough heat transfer enhancement if the pressure drop penalty is a major concern in certain cooling designs. In these cases, the closer rib spacing can be used due to the increased rib-side area for convection (fin effect), in addition to the heat transfer enhancement. For example, smaller gas turbine blades have larger blockage ribs with 10-20\% rib height-to-hydraulic diameter ratio at closer spacing with 3-5 rib spacing-to-height ratio reported by Taslim et al. (1997, 1998a, 1998b).
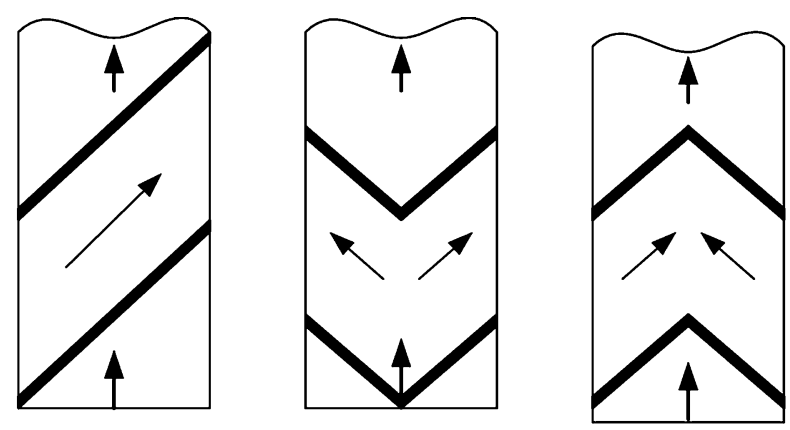

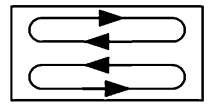

45 deg. angled rib

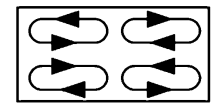

45 deg. V-shaped angled rib

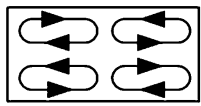

Inverted 45 deg. Vshaped angled rib
FIGURE 3

Conceptual view of secondary flow vortices induced by $45^{\circ}$ angled $45^{\circ} \mathrm{V}$-shaped ribs.

\section{EFFECTS OF ROTATION ON COOLANT PASSAGE HEAT TRANSFER}

\section{Rotational Effect on Internal Cooling}

Rotation induces Coriolis and centrifugal forces that produce cross-stream secondary flow in the rotating coolant passages; therefore, heat transfer coefficients in rotor coolant passages are very much different from those in non rotating frames. Figure 4 shows the schematic secondary flow and axial flow distribution in a rotating two-pass square channel. Figure 5 shows the predicted secondary flow, axial flow, and temperature distribution in a rotating square channel with radial outward flow. One important finding from recent studies is that rotation can greatly enhance heat transfer on one side of the cooling channel and reduce heat transfer on the opposite side of the cooling channel due to rotating-induced secondary flow, depending on the radial outflow or inflow of the cooling passages. Without considering rotational effect, the coolant passage would be over-cooled on one side while over-heated on the opposite side. Recent studies focus on the combined effects of rotation, channel shape, orientation, and aspect ratio on rotor coolant passage heat transfer with various high performance rib turbulators. Results show that the channel shape, orientation, and aspect ratio significantly change local heat transfer coefficient distributions in rotor coolant passages with rib turbulators. To better understand the complex 3-D flow physics in the complicated blade internal coolant passage geometry, recent efforts also focus on the computational flow and heat transfer using the RANS method with various turbulence models. Results indicate that the second-moment turbulence closure model provides better flow and heat transfer predictions than the standard $\mathrm{k}-\varepsilon$ model. The existing and modified CFD codes would become useful tools for rotor coolant passage heat transfer prediction and coolant flow optimization and management. Recent studies extend to also focus on the effects of rotation on impingement cooling and pin fin cooling in the blade leading edge and trailing edge region, respectively. Results show that rotation creates a negative impact on rotor coolant passages with impinging jets. In general, rotation reduces the impingement cooling effect due to jet deflection away from the impinged surface.

\section{Heat Transfer in Rotating Coolant Passages with Square Cross Section}

Heat transfer in rotating multi-pass coolant passages with square cross section and smooth walls was reported by Wagner et al. (1991). Results show that the heat transfer coefficient can enhance 2-3 times on the trailing surface and reduce up to $50 \%$ on the leading surface for the first-pass radial outward flow passage; however, the reverse is true for the second-pass radial inward flow passage due to the flow direction change. Results also show that the heat transfer difference between leading and trailing surfaces is greater in the first-pass than that in the secondpass due to the centrifugal buoyancy opposite to the flow direction. Heat transfer in rotating multi-pass coolant passages with 

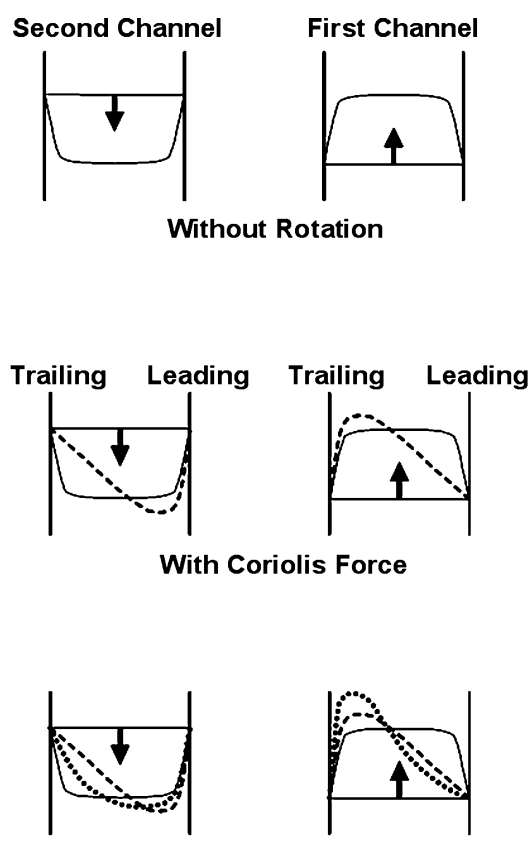

With Coriolis Force With Buoyancy Force

Direction of Rotation

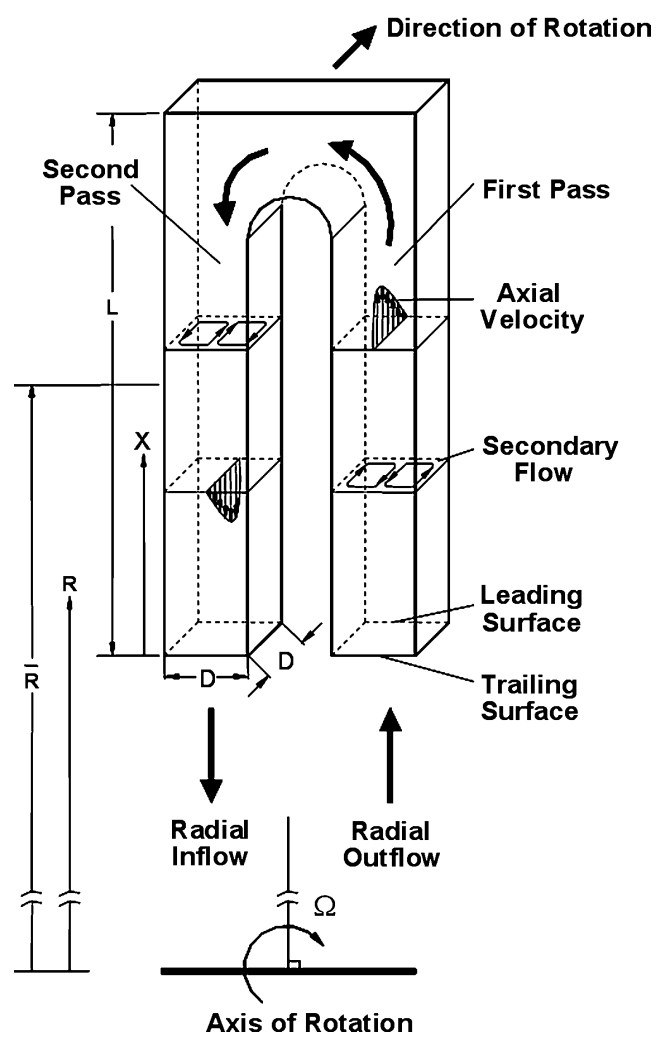

FIGURE 4

Conceptual view of a two-pass rotating coolant flow distribution by Han et al. (1993).

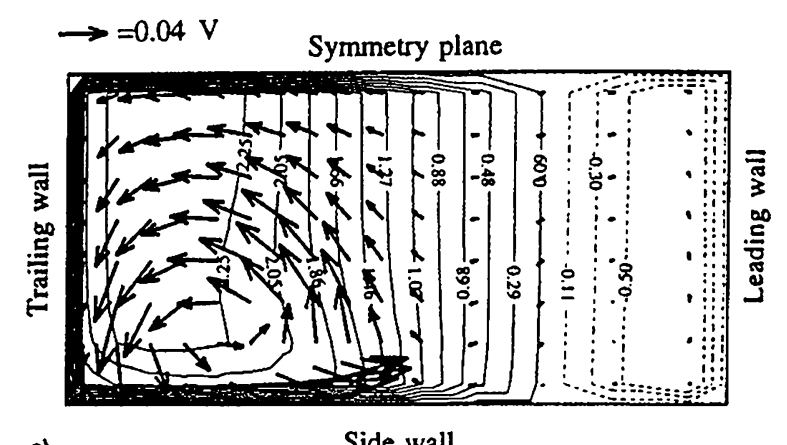

a)

Side wall

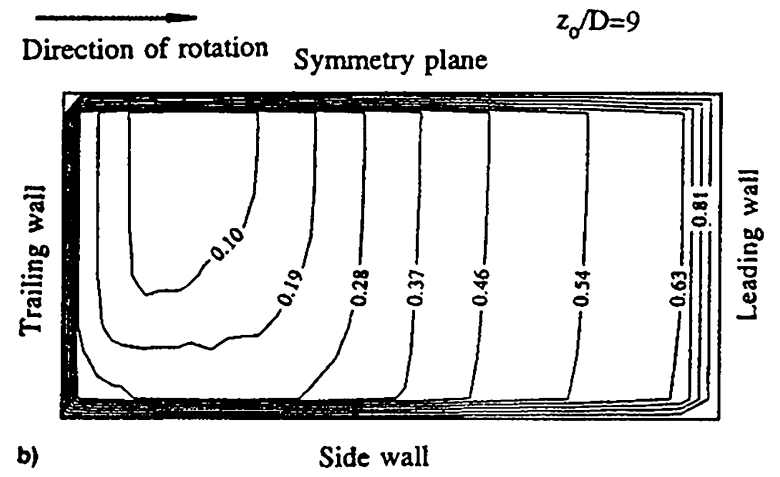

FIGURE 5

Predicted secondary flow, axial flow, and temperature distribution in a rotating square channel with radial outward flow, collected in Han et al. (2000).

square cross-section with $45^{\circ}$ rib turbulated walls, as shown in Figure 6, was reported by Johnson et al. (1994). Results show that rotation and buoyancy, in general, have less effect on the rib turbulated coolant passage than on the smooth-wall coolant passage. This is because the heat transfer enhancement in the ribbed passages is already up to 3.5 times higher than in the smooth passages; therefore, the rotational effect is still important but with a reduced percentage. Results also show that, like a non rotating channel, the $45^{\circ}$ ribs perform better than $90^{\circ}$ ribs and subsequently better than the smooth channel.

\section{Wall Heating Condition Effect on Rotating Coolant Passage Heat Transfer}

From the above analyses, the rotation effect on channel heat transfer comes from the Coriolis and centrifugal forces. The centrifugal force is known as rotation buoyancy when there is a temperature difference between the coolant and the channel walls at rotating conditions. Since the temperature difference between the coolant and the channel walls varies along the coolant passages, so does the rotation buoyancy. Therefore, it is expected that the channel wall heating conditions would affect rotor coolant passage heat transfer. The channel heating conditions imply that the channel walls may be at the same temperature (or heat flux) in both stream-wise and circumferential 

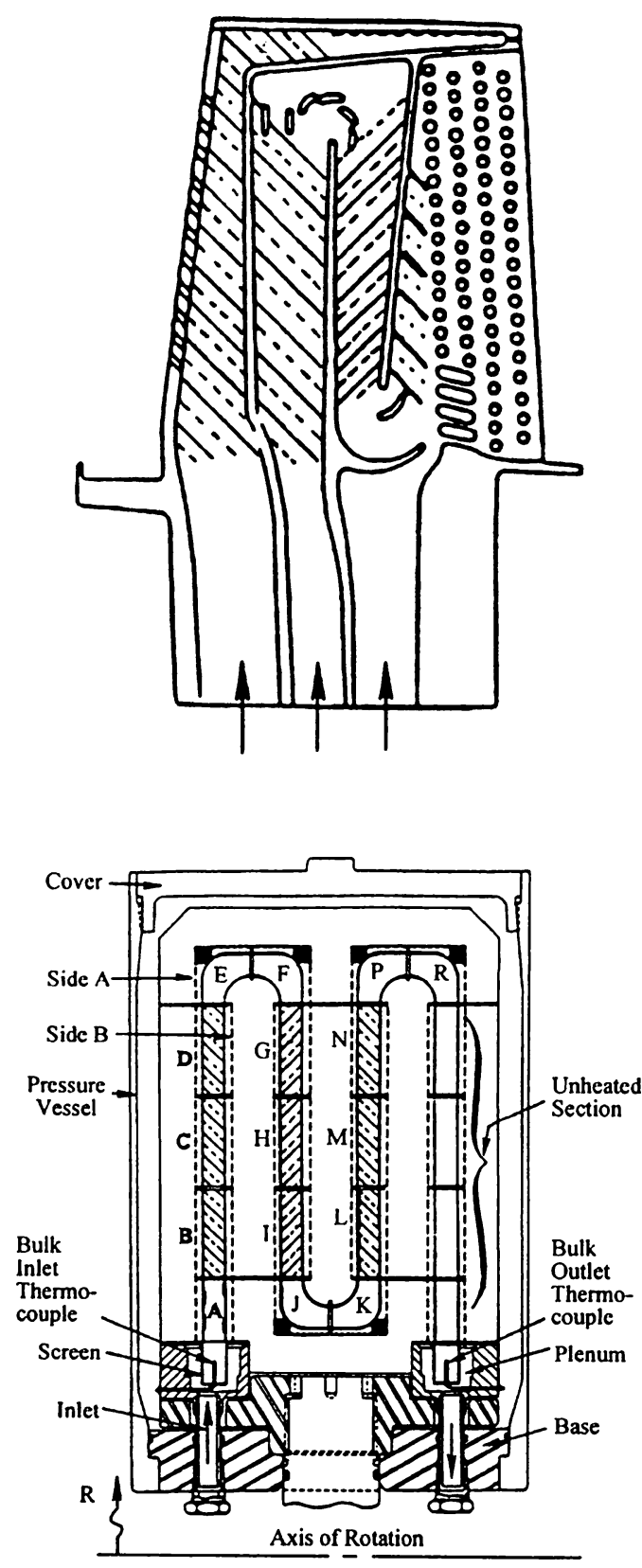

FIGURE 6

Multipass rotating channel with $45^{\circ}$ ribs used by Johanson et al. (1994b) to simulate a turbine rotor blade coolant passage.

directions, or the trailing wall temperature may be higher than the leading wall temperature in real turbine blade cooling applications. Han et al. (1993) studied the uneven wall temperature effect on rotating two-pass square channels with smooth walls. They concluded that in the first pass, the local uneven wall temperature interacts with the Coriolis force-driven secondary flow and enhances the heat transfer coefficients in both leading and trailing surfaces, with a noticeable increase in the leading side, as compared with the uniform wall temperature case. However, the uneven wall temperature significantly enhances heat-transfer coefficients on both leading and trailing surfaces. Parsons et al. (1994) and Zhang et al. (1995) studied the influence of wall heating condition on the local heat transfer coefficient in rotating two-pass square channels with $90^{\circ}$ ribs and $60^{\circ}$ ribs on the leading and trailing walls, respectively. They concluded that the uneven wall temperature significantly enhances heat transfer coefficients on the first-pass leading and second-pass trailing surfaces as compared with the uniform wall temperature condition.

\section{Effect of Channel Orientation with Respect to the Rotation Direction}

Since the turbine blade is curved, the rotor blade cooling passage can have different channel orientations with respect to the rotating plane. Johnson et al. (1994) studied the effects of rotation on the heat transfer for smooth and $45^{\circ}$ ribbed serpentine channels with channel orientations of 0 and $45^{\circ}$ to the axis of rotation, as shown in Figure 7. They found that the effects of Coriolis and buoyancy forces on heat transfer in the rotating

a) Blade With Foward Flowing Coolant

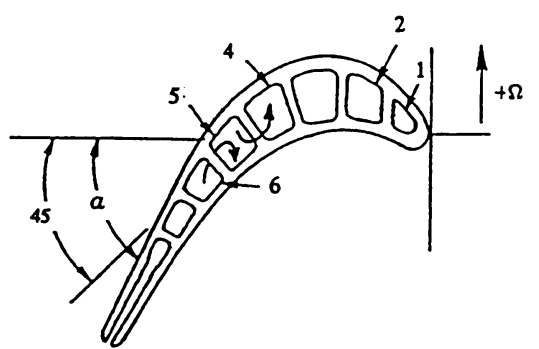

b) Heat Transfer Model
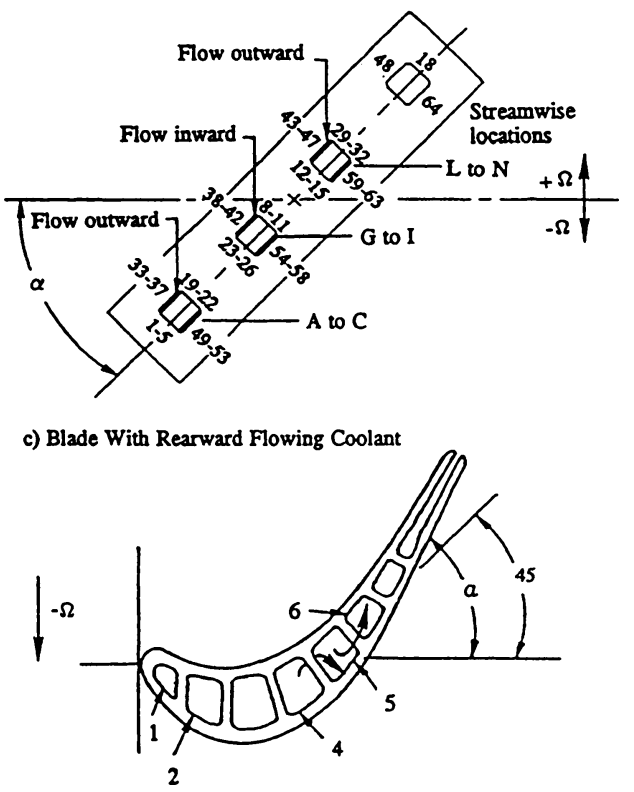

FIGURE 7

Model orientation and rotation directions used by Johanson et al. (1994a). 

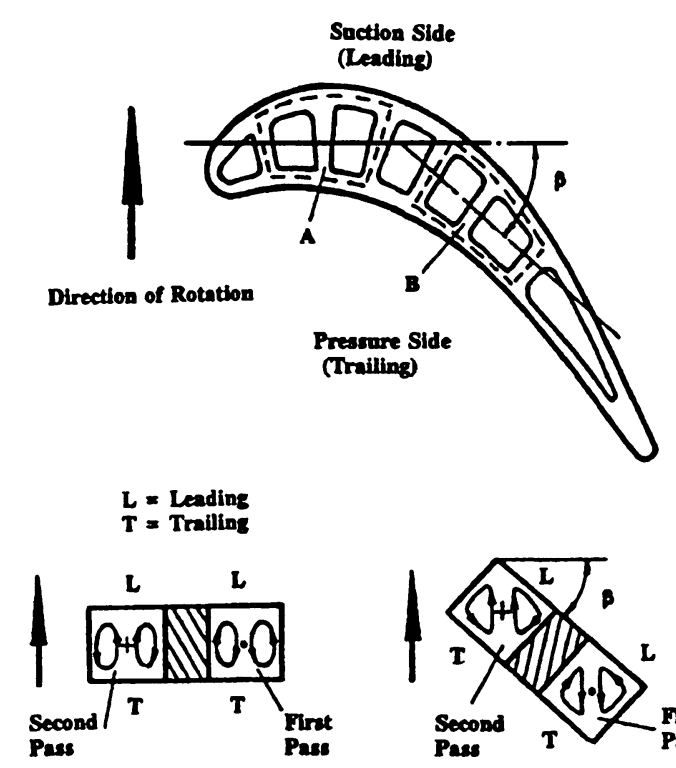

Model Orientation A $(P=0)$

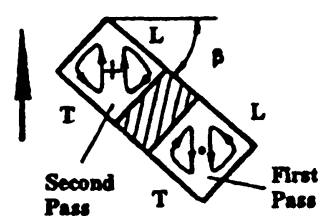

Model Orientation B $(\beta=45)$

FIGURE 8

Schematic of cooling-channel orientations in an air foil used by Parsons et al. (1995).

channel are decreased with the channel at $45^{\circ}$ compared to the results at $0^{\circ}$. This implies that the difference in heat transfer coefficient between leading and trailing surfaces due to rotation will be reduced when the channel has an angle to the axis of rotation. Parsons et al. (1995) used $60^{\circ}$ angled ribs, Dutta and Han (1996) used high performance broken V-shaped ribs, and Al-Hadhrami and Han (2002) used parallel and crossed $45^{\circ}$ angled ribs in rotating two-pass square channels to study the effect of channel orientation on heat transfer. The channel orientation with respect to the rotation axis influences the secondary flow vortices induced by rotation, as shown in Figures 8 and 9 shows the secondary flow developed by broken V-shaped ribs could interact with the secondary flow of rotation and a new flow pattern might be established. Figure 10 shows the two cell vortices induced by rotation, the two cell vortices induced by the parallel $45^{\circ}$ ribs, and the single cell vortex induced by the crossed $45^{\circ}$ ribs. They concluded that the broken $\mathrm{V}$-shaped ribs are better than the $60^{\circ}$ angled ribs; the parallel $45^{\circ}$ angled ribs are better than the crossed $45^{\circ}$ angled ribs. In general, the difference between leading and trailing wall heat transfer coefficients is reduced for the channel with a $45^{\circ}$ angle to the axis of rotation.

\section{Heat Transfer in Rotating Coolant Passages with Triangular Cross Section}

Rotating coolant passages with triangular cross section might be used on some portion of the blade in order to provide compact channel structure and good cooling efficiency. Dutta

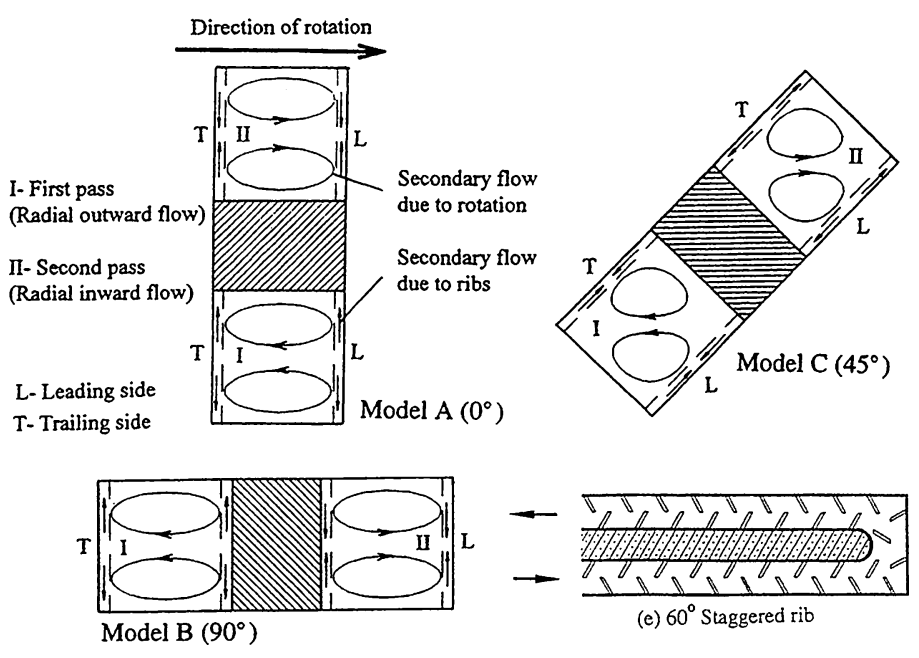

FIGURE 9

Conceptual view of the secondary flow vortices induced by rotation, channel orientation, and broken V-shaped ribs used by Dutta and Han (1996).
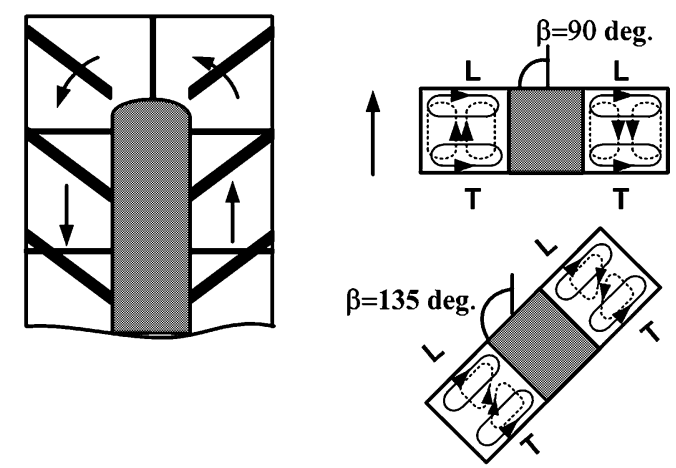

Parallel 45 Deg. Angled Ribs
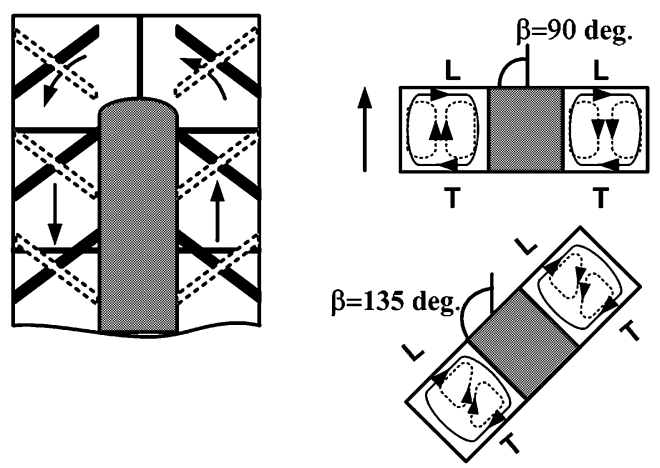

Crossed 45 Deg. Angled Ribs

FIGURE 10

Conceptual view of the secondary flow vortices induced by rotation, and channel orientation in a two-pass square duct (dash lines: rotation-induced vortices; solid lines: rib-induced vortices) from Al-Hadhrami and Han (2002). 


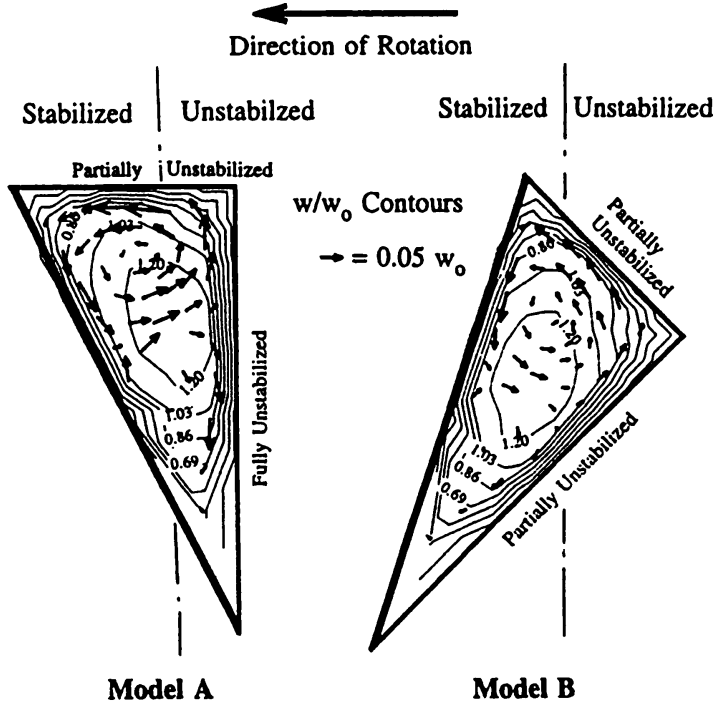

(a)

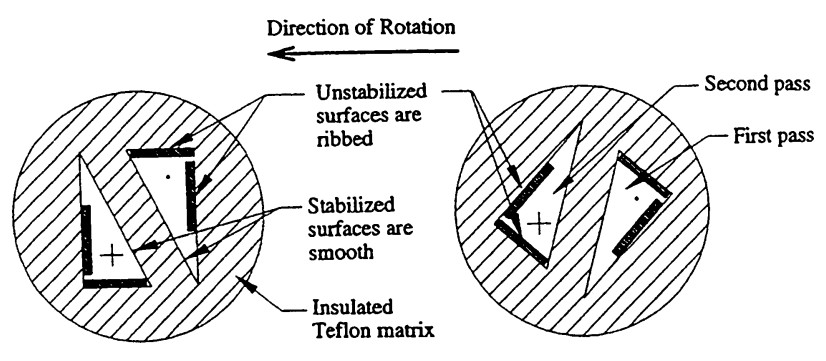

Model Orientation A

Model Orientation B

(b)

FIGURE 11

(a) Prediction of secondary flow vectors and axial flow contours in rotating triangular channels with different model orientations from Dutta et al. (1996b); (b) Combined effects of channel cross section and rotation directions from Dutta et al. (1996a).

et al. (1996a, 1996b) studied the effect of rotation on the heat transfer coefficients in two-pass triangular channels with smooth and ribbed walls, as shown in Figures 11a and 11b. For the locations in the first pass, the triangular-duct heat transfer coefficients are mostly contained within the upper and lower limits imposed by the square duct. This is because in a triangular duct, there is less space for the coolant to form secondary flow by rotation (Figure 11a). However, in the second pass, the leading surface of the triangular duct shows much higher heat transfer coefficients than the square duct. This is due to more mixing and favorable secondary flow in the $180^{\circ}$ turn for the triangular duct geometry. The ribbed duct results are compared with smooth-walled data. The first-pass trailing surface and second-pass leading surface show an increase in the heat transfer coefficient with increasing rotation. They also found that channel orientation and uneven wall temperature have a significant effect on the surface heat transfer coefficient distributions.

\section{Heat Transfer in Rotating Coolant Passages with Rectangular Cross Section}

Most of the above-mentioned studies dealt with square channels. However, a rectangular coolant passage is of high importance in order to maintain the integrity of gas turbine blade internal cooling design. The curved shape of the turbine blade may prohibit the efficient use of square cross-sectional coolant flow channels. It is quite common to find rectangular cooling passages, particularly moving from the mid-chord to the trailing edge of the blade; the channels must become more rectangular as the blade becomes thinner. This thinning of the channel changes the effective secondary flow pattern from that of a square duct. For this reason, one cannot simply apply the knowledge of the rotationally induced flow pattern and the associated surface heat transfer coefficients in a square channel to that of a rectangular channel. However, very few experimental heat transfer data on a rectangular coolant passage are available in the literature. Azad et al. (2001) and Al-Hadhrami et al. (2002) studied heat transfer in a two-pass rectangular rotating channel (aspect ratio $=2: 1$ ) with $45^{\circ}$ angled ribbed walls and $45^{\circ} \mathrm{V}$-shaped ribbed walls, respectively, including the effect of channel orientation with respect to the axis of rotation. Figure 12 shows the two cell vortices induced by rotation, the two cell vortices induced by the $45^{\circ}$ parallel ribs, and the single cell vortex induced by the $45^{\circ}$ crossed ribs. Figure 13 shows the two cell vortices induced by rotation, the four cell vortices induced by $45^{\circ} \mathrm{V}$-shaped ribs, and the two cell vortices induced by $45^{\circ}$ crossed V-shaped ribs. They found that the effect of rotation on the two-pass rectangular channel is very similar to that on the two-pass square channel except the leading surface heat transfer coefficient does not vary much with the rotation compared with the square channel case. The results show that $45^{\circ}$ parallel angled ribs produce a better heat-transfer augmentation than $45^{\circ}$ crossed ribs; $45^{\circ} \mathrm{V}$-shaped ribs are better than $45^{\circ}$ crossed V-shaped ribs and subsequently better than $45^{\circ}$ parallel angled ribs. The difference in heat transfer coefficients between leading and trailing surfaces in a smooth channel is smaller when the channel has an angle with respect to the axis of rotation. This heat transfer coefficient difference is reduced further in ribbed channel cases.

Griffith et al. (2001) studied heat transfer in a single pass rectangular channel (aspect ratio $=4: 1$ ) with smooth and $45^{\circ}$ angled ribbed walls, as shown in Figure 14, including the effect of channel orientation with respect to the axis of rotation. Results show that the narrow rectangular passage exhibits a much higher heat transfer enhancement for the ribbed surface than the square and 2:1 channels previously investigated. Also, channel orientation significantly affects the leading and side surfaces, yet does not have much affect on the trailing surfaces for both smooth and ribbed surfaces. Therefore, this investigation has determined that 

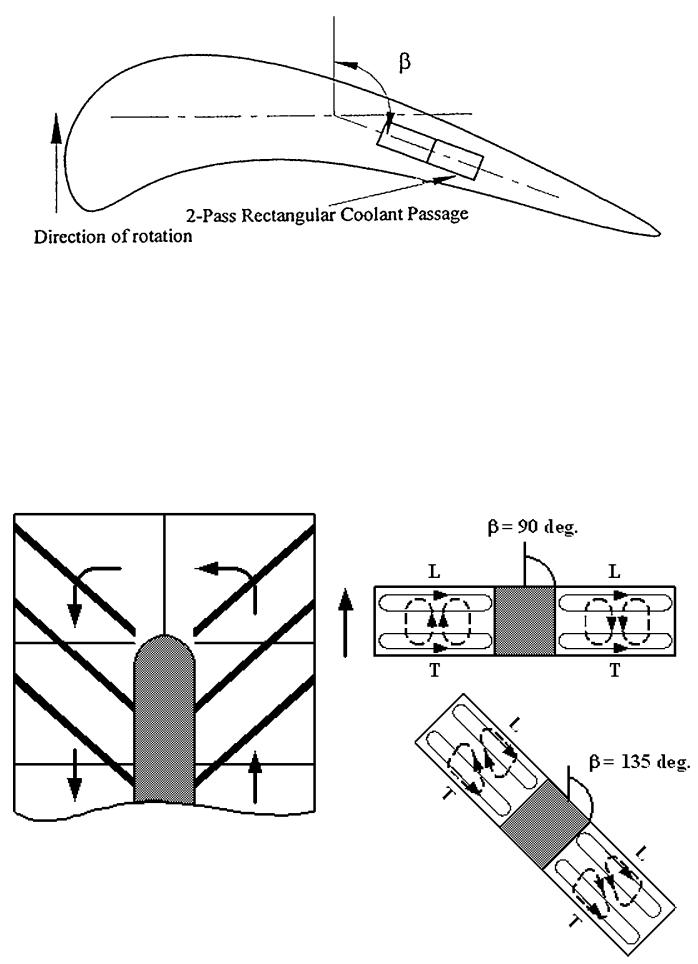

Parallel 45 Deg. Angled Ribs
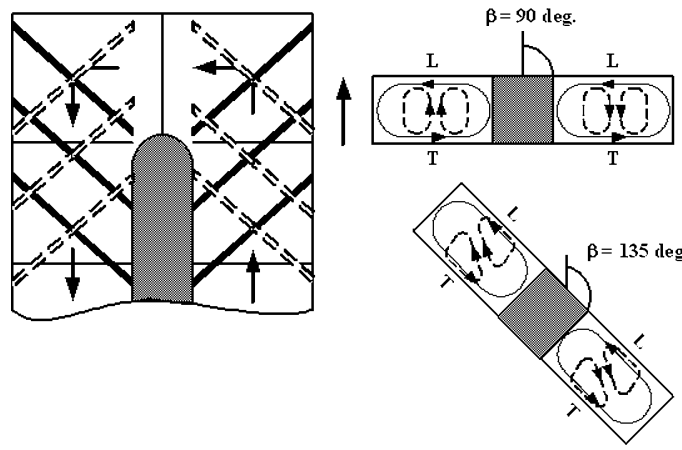

Crossed 45 Deg. Angled Ribs

FIGURE 12

Conceptual view of the secondary flow vortices induced by rotation and channel orientation in a two-pass rectangular channel (dash lines: rotation-induced vortices; solid lines: rib-induced vortices) from Azad et al. (2001).

span-wise variations in the heat transfer distribution of rectangular cooling passages exist, and that the enhancement is a function of channel orientation with respect to the axis of rotation, surface configuration (such as smooth or $45^{\circ}$ angled ribbed walls), and channel aspect ratio. Willett and Bergles (2000) studied heat transfer in a single pass narrow, 10:1 smooth rectangular channel oriented at an angle to the axis of rotation. They focused on the rotating buoyancy effect on local heat transfer coefficients. They

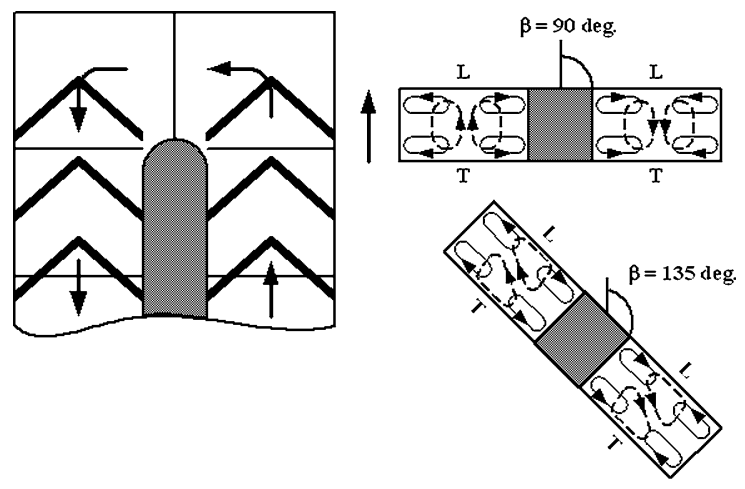

Parallel 45 Deg. V-shaped Ribs
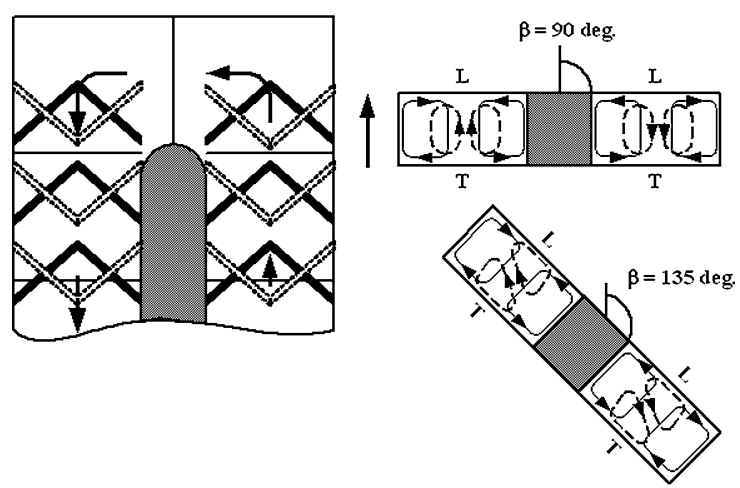

Crossed 45 Deg. V-shaped Ribs

FIGURE 13

Conceptual view of the secondary flow vortices induced by rotation and channel orientation in a two-pass rectangular channel (dash lines: rotation-induced vortices; solid lines: rib-induced vortices) from Al-Hadhrami et al. (2002).

found that the channel orientation induced a significant variation in the heat transfer coefficient in the span-wise direction. They also found that the heat transfer coefficient at the far aft end of the trailing surface is a very strong function of rotation buoyancy.

\section{Heat Transfer in Rotating Coolant Passages with Trapezoidal Cross Section}

In the literature, most internal coolant passage geometries are idealized as square, triangular, or rectangular cross-sectional channels. Rathjen et al. (2001) studied detailed heat/mass transfer distributions in a rotating two-pass coolant channel with engine-near cross section and smooth walls. The test section consisted of a first-pass with trapezoidal cross section for radial outward flow, a $180^{\circ}$ bend with a $90^{\circ}$ turning vane, and a secondpass with a larger trapezoidal cross section for radial inward flow, as shown in Figure 15. Note that the channel cross section and orientation in this study are for the mid-chord to leading edge 


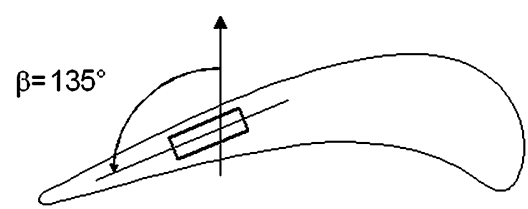

4:1 Aspect Ratio Channel

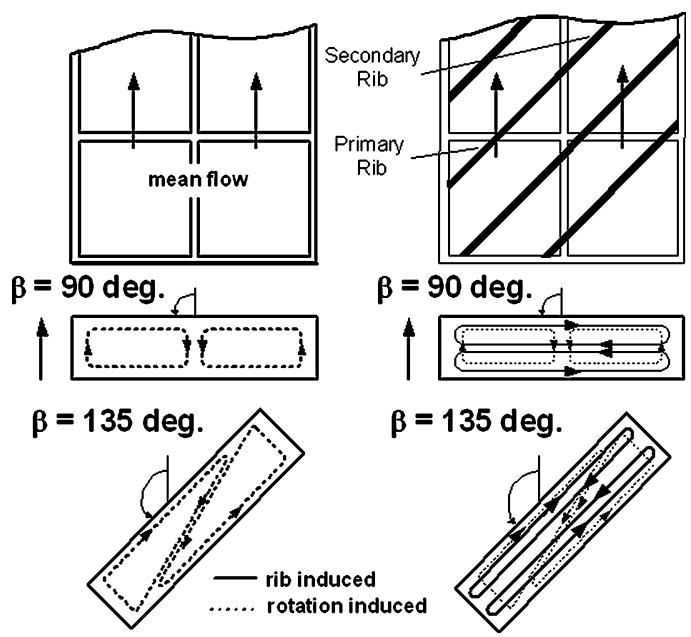

FIGURE 14

Outward flow rectangular test section with smooth walls and $45^{\circ}$ parallel angled ribs on leading and trailing surfaces by Griffith et al. (2001).

of real rotor coolant passage geometry. They used the naphthalene sublimation technique to obtain detailed heat/mass transfer distributions and CFD for complex flow field simulations. They found that the heat/mass transfer distributions in the bend and in the region after the bend show strong gradients with several separation zones and the flow is forced to follow the turbine
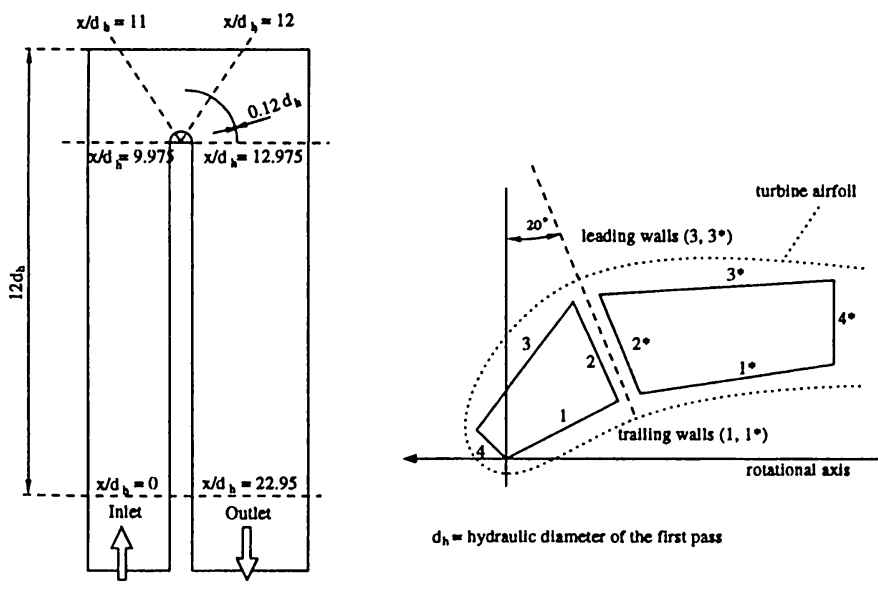

$d_{h}=$ hydraullc diameter of the first pass

FIGURE 15

Test model geometry of a two-pass trapezoidal channel used by Rathjen et al. (2001). blade shape (i.e., channel shape and orientation with respect to the axis of rotation).

\section{Computational Heat Transfer in Rotating Coolant Passages}

In recent years, several researchers have made computational studies on internal cooling channels of the rotating blade. Numerical predictions provide the details that are difficult to obtain by experiments. Moreover, the increase in computation power in desktop computers has made it economical to optimize the design parameters based on numerical analyses. Most common models are based on a two-equation turbulence model, namely, the k- $\varepsilon$ model, low Reynolds number k- $\varepsilon$ model, the two-layer $\mathrm{k}-\varepsilon$ model, and the low Reynolds number k- $\omega$ model. Advanced Reynolds stress model and the second moment closure model are also employed. In general, it has been proven by many investigators that the $\mathrm{k}-\varepsilon$ model cannot correctly predict the complex flow and heat transfer behaviors in rotating two-pass rectangular channels with angled rib-type turbulence promoters typically in the rotor coolant passage design. This is simply due to the isotropic turbulence assumption and near surface wall function requirement made by using the $\mathrm{k}-\varepsilon$ model. However, there are much more complicated flow fields in the rotor coolant passage design such as rotating three-dimensional asymmetric flow, $180^{\circ}$ flow turning and recirculation, angled rib-induced flow separation and secondary flow, etc. It has been found by previous investigators that the low Reynolds number $\mathrm{k}-\omega$ model does predict reasonably well on the flow and heat transfer in typical two-pass rotating channels with angled ribbed walls. This is attributed to the fact that turbulence dissipation is specified in terms of the turbulent kinetic energy in the near wall region to replace wall function and very fine grid computation is used toward the surface. As expected, the second moment closure model provides the best flow and heat transfer characteristics in typical rotating two-pass channels with angled rib turbulators. In this model, six additional transport equations are required to be solved in a 3-D turbulent flow, and the eddy diffusivity in the momentum transport equation is replaced by the source terms developed from the turbulent Reynolds stress tensor. Therefore, more computing time is required. In the following, only a few representative studies using the low Reynolds number k- $\omega$ model and second moment closure model are mentioned.

Stephens et al. (1997) performed an investigation of the effect of $45^{\circ}$ angled ribs on the heat transfer coefficients in a rotating two-pass square channel using a low-Re number k- $\omega$ turbulence model. They studied the effects of compressible flow Reynolds numbers, rotation numbers, and buoyancy parameters. They found that the angled ribs create an asymmetric heat transfer coefficient distribution. This is because the angled ribs developed a secondary flow of their own, and that interacts with the secondary flow developed in rotation. In the leading wall of the radial outward flow, heat transfer is highest at the upstream side of the rib and in the inter-rib region next to the inner sidewall. However, for the radial inward flow after the $180^{\circ}$ bend, 
heat transfer is highest on the upstream side of the rib and in the inter-rib region next to the outer sidewall. They did not compare with the experimental data. Bonhoff et al. (1997) calculated the heat transfer coefficients and flow fields for rotating U-shaped square channels with $45^{\circ}$ angled ribs by using a Reynolds stress turbulence model with wall functions in the FLUENT CFD code. Their results show that the heat transfer coefficients of the rotating first-pass leading and trailing surfaces are under-predicted by the experimental data. Iacovides and Raisee (1999) explored turbulence modeling issues related to the computation of flow and heat transfer in internal cooling passages of turbine blades with $90^{\circ}$ ribs. They found that the low-Re differential stress model (DSM) reproduces the turbulence field more reasonably than the $\mathrm{k}-\varepsilon$ model. Jang et al. (2001) predicted flow and heat transfer in a single pass rotating square channel with $45^{\circ}$ angled ribs by the second moment closure model. Figure 16 shows the prediction of streamline velocity vector distribution for ribbed duct. Their heat transfer coefficient prediction was well compared with the
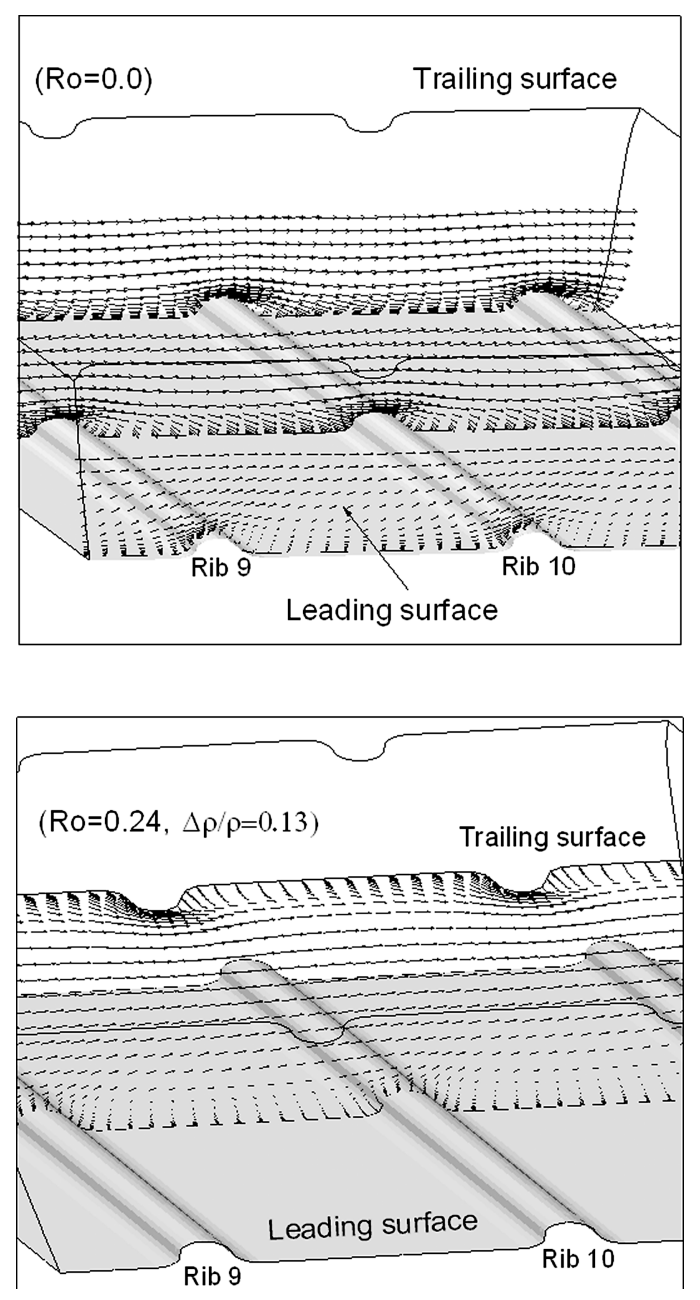

FIGURE 16

Streamwise velocity vector distribution fo ribbed duct from Jang et al. (2001).

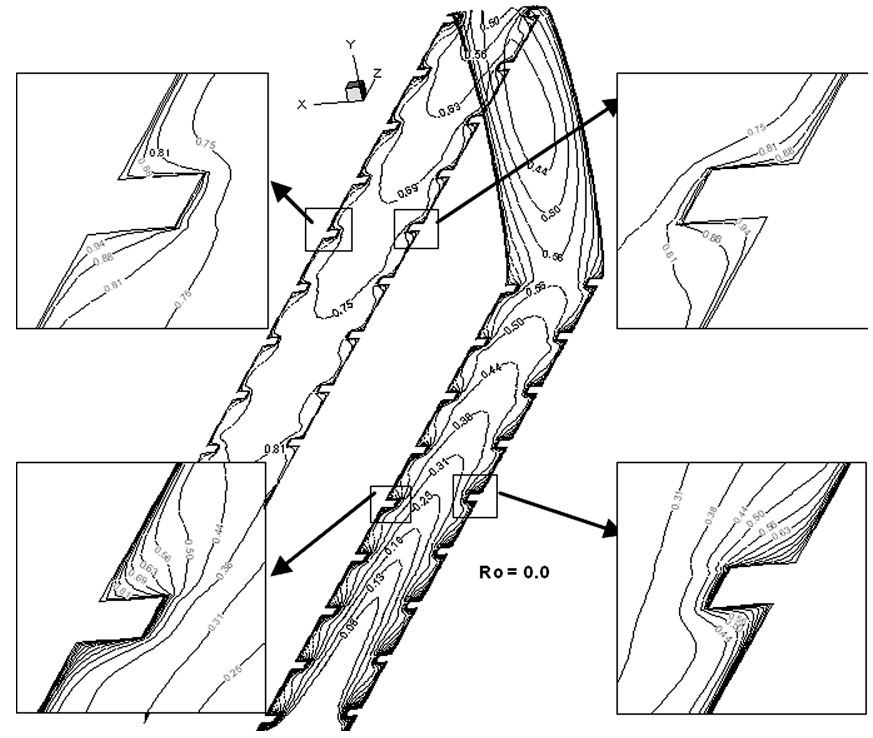

FIGURE 17

Temperature contours midway between the inner and outer surfaces for case $1(\mathrm{Ro}=0)$ from Al-Qahtani et al. (2001).

experimental data. This has affirmed the superiority of the second moment closure model compared to the simpler isotropic eddy viscosity k- $\varepsilon$ model. The advantage of the second moment closure model is that it resolves the near-wall flow all the way to the solid wall rather than using log-law assumption in the viscous sub-layer. With this near-wall closure, surface data like heat transfer coefficients and friction factors can be evaluated directly from velocity and temperature gradient on the solid wall. Al-Qahtani et al. (2001) predicted flow and heat transfer in a two-pass rotating rectangular channel (aspect ratio $=2: 1$ ) with $45^{\circ}$ angled ribs by the same second moment closure model used by Jang et al. (2001). Figure 17 shows the prediction of temperature countours midway between the inner and outer surfaces. They found that the predicted heat transfer coefficient compared reasonably well with the experimental data.

\section{Rotational Effect on Impingement Cooling}

Jet impingement heat transfer is most suitable for the leading edge of the blade where the thermal load is highest and a thicker cross section of this portion of the blade can suitably accommodate impingement cooling. There are some studies focused on the effects of jet-hole size and distribution, jet-to-target surface distance, spent-air cross flow, cooling channel cross section, and the target surface shape on the heat transfer coefficient distribution. However, most impingement cooling studies are for stator blades; only a few studies focus on rotor blade impingement cooling. Epstein et al. (1985) studied the effect of rotation on impingement cooling in the leading edge of a blade. Figure 18 shows schematics of their impingement test section. They reported that the rotation decreases the impingement heat transfer, but the effective heat transfer is better than a smooth rotating 

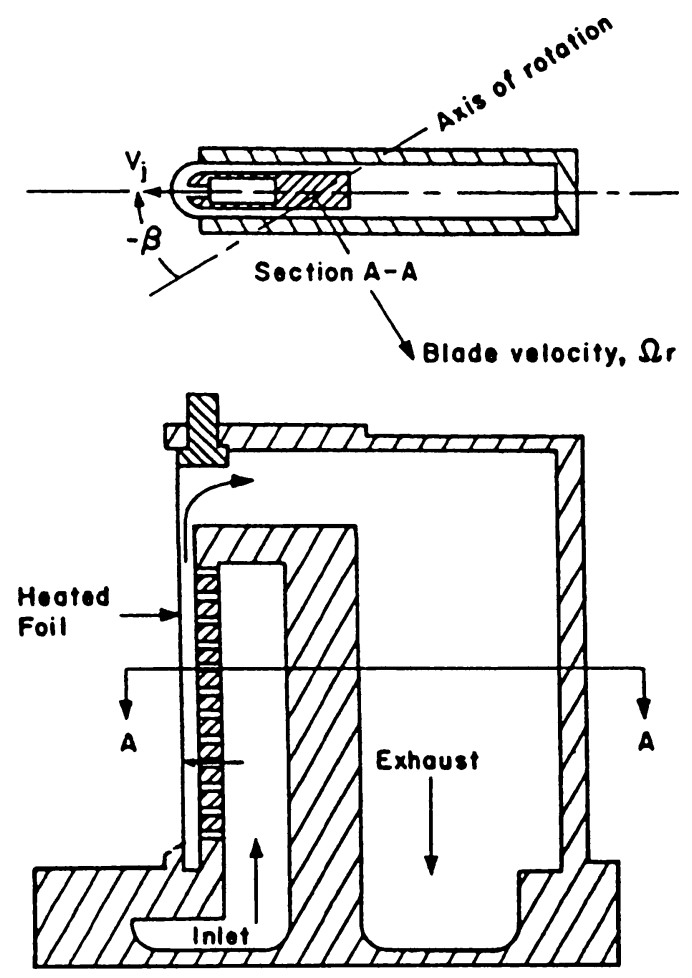

FIGURE 18

Schematic of a leading-edge impingement test facility used by Epstein et al. (1985).

channel. The zero staggered of cooling jets (i.e., jet direction is perpendicular to rotation direction) in Figure 18 shows lower heat transfer coefficients compared to that with a staggered angle. Mattern and Hennecke (1996) reported the effect of rotation on the leading edge impingement cooling by using the naphthalene sublimation technique. Their experiment did not include the rotating buoyancy effect. The jet direction has an offset angle with respect to the rotation direction as shown in Figure 19. They found that the rotation decreases the impingement heat transfer for all staggered angles. The effect of rotation is least when jet direction has an angle of $45^{\circ}$ to rotation direction. However, a maximum of $40 \%$ reduction in heat transfer is noted when jet direction is perpendicular to rotation direction. This may be because the Coriolis force creates a swirl action on the spent flow and also deflects the jet when jet direction is parallel to rotation direction. Glezer et al. (1998) studied the effect of rotation on swirling impingement cooling in the leading edge of a blade. Figure 20 shows schematics of their swirling impingement test section. They found that screw-shaped swirl cooling can significantly improve the heat-transfer coefficient over a smooth channel and the improvement is not significantly dependent on the temperature ratio and rotational forces.

Parsons et al. (1998) studied the effect of rotation on impingement cooling in the mid-chord region of the blade. Figure 21 shows that a central chamber serves as the pressure chamber, and jets are released in either direction to impinge on two heated

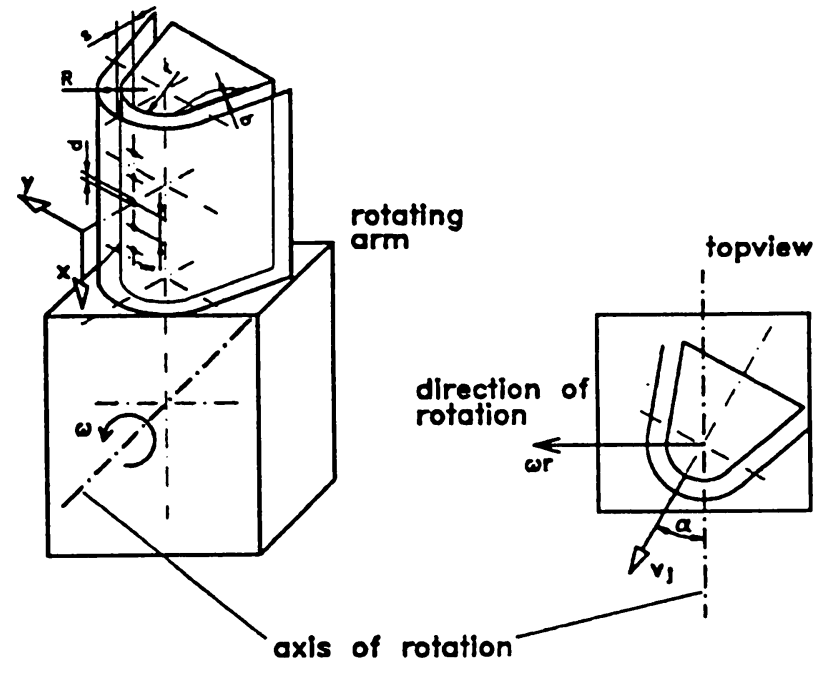

FIGURE 19

Schematic of the leading-edge impingement configuration used by Mattern and Henneckel (1996).

surfaces. The jet impinging directions have different orientations with respect to the direction of rotation. They reported that the rotation decreases the impingement heat transfer on both leading and trailing surfaces with more effect on the trailing side (up to $20 \%$ heat transfer reduction). Akella and Han (1998) studied the effect of rotation on impingement cooling for a twopass impingement channel configuration with smooth walls. The difference from the earlier experiment by Parsons et al. (1998) is that spent jets from the trailing channel are used as cooling jets for the leading channel. Therefore, the cross-flow in the trailing side is radial outward; for the leading side, it is radial inward. They reported that irrespective of the direction of rotation, the heat transfer coefficient on the first-pass and second-pass impinging wall decreases up to $20 \%$ in the presence of rotation.

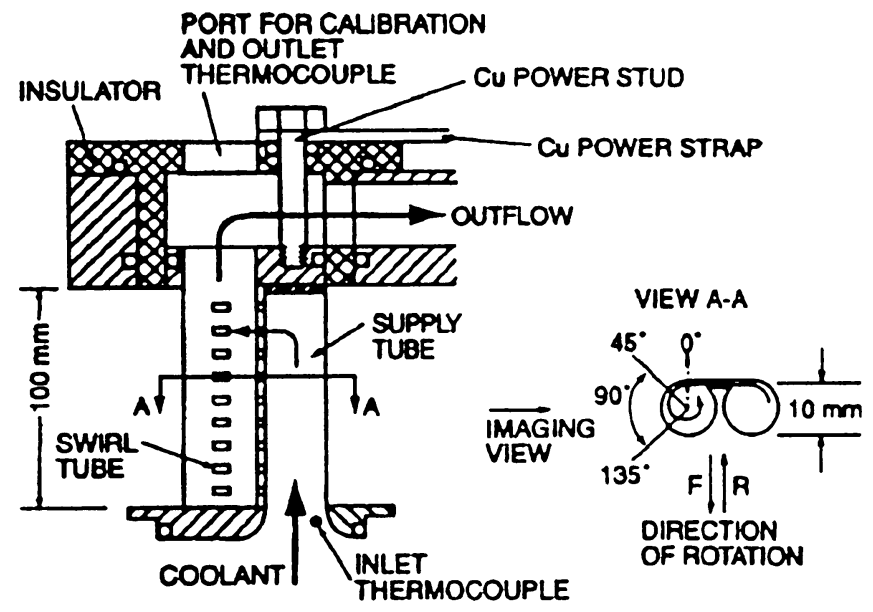

FIGURE 20

Schematic of swirl tube test facility used by Glezer et al. (1998). 

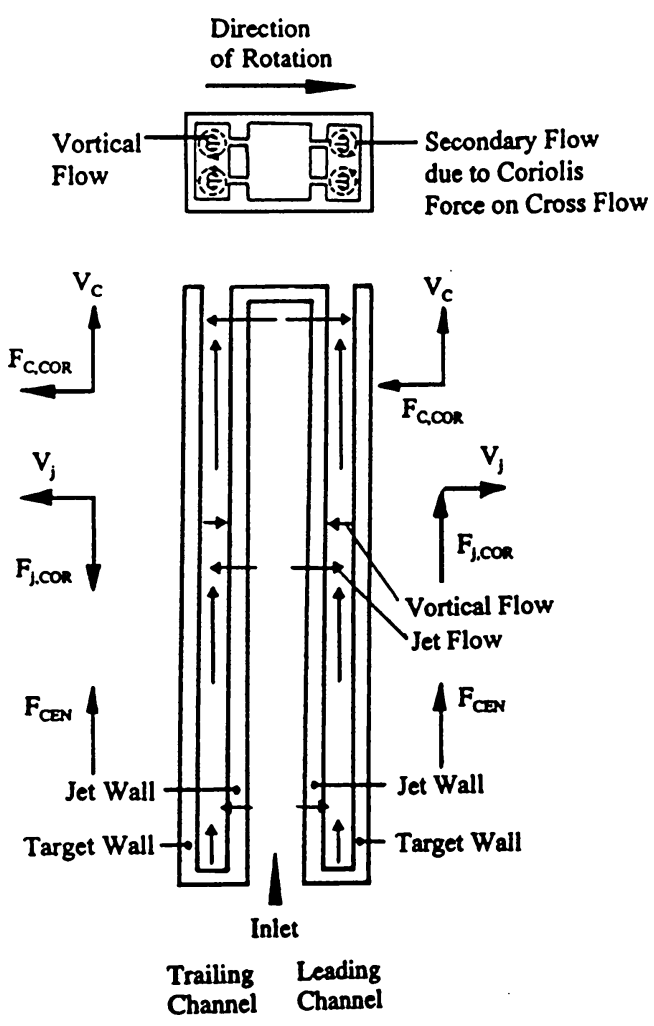

FIGURE 21

Schematic of the vortices and rotational forces for the test facility of Parsons and Han (1998).

Akella and Han (1999) included $45^{\circ}$ angled ribs in the target surfaces of their two-pass impingement channel with rotation as shown in Figure 22. They reported that jet impingement on the ribbed wall can provide $10-50 \%$ more heat transfer com-

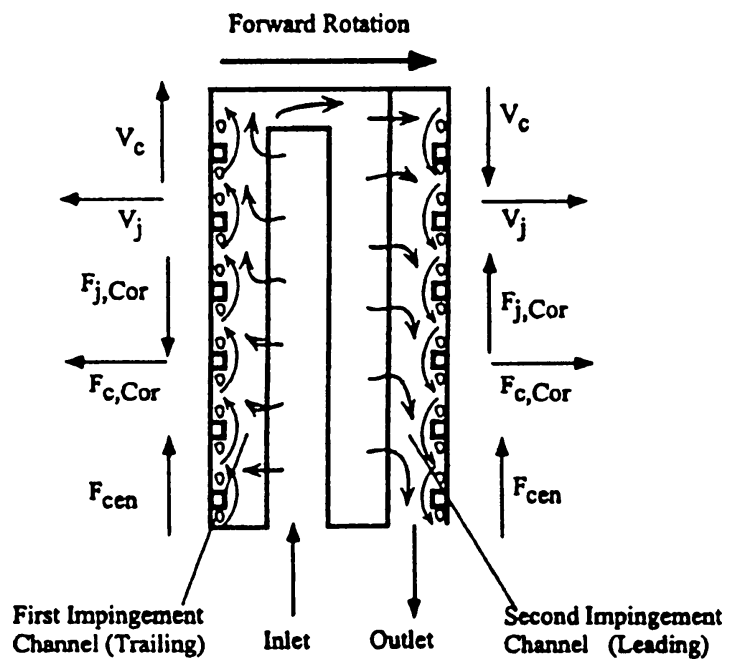

FIGURE 22

Schematic of the flow and rotational forces in rotating impingement channel of Akella and Han (1999). pared to that on the smooth wall for jet Reynolds number increasing from 4,000 to 10,000 . This is because the angled ribinduced secondary flow gets stronger with higher cross-flow at higher jet Reynolds number. They also found that the rotation decreases impingement heat transfer on the first-pass and second-pass ribbed wall.

\section{EFFECTS OF UNSTEADY TURBULENCE ON FILM COOLING}

\section{Recent Studies on Turbine Blade Film Cooling}

In film cooling, relatively cool air is injected from the inside of the blade to the outside surface, which forms a protective layer between the blade surface and hot mainstreams. Performance of film cooling primarily depends on the coolant-to-mainstream pressure ratio (blowing ratio), temperature ratio (density ratio), film hole geometry (hole size, spacing, shape, angle from the surface, and number of rows), and location (leading edge, trailing edge, pressure and suction sides, end-wall, and blade tip) under representative engine flow conditions (Reynolds number, Mach number, combustion generated high free-stream turbulence, and unsteady wake flow). In recent years, there have been many studies in turbine blade film cooling. For example, Abhari and Epstein (1994) studied rotor blade film cooling, Nirmalan and Hylton (1990) reported on linear cascade nozzle guide vane film cooling, Camci and Arts (1985) studied the linear cascade blade film cooling, Harasgama and Burton (1992) presented annual cascade nozzle guide vane end-wall film cooling, Mehendale and Han (1992) studied the modeled blade leading edge film cooling, and Kim et al. (1995) reported on the modeled blade tip film cooling. A detailed literature survey in film cooling study can be found in Han and Ekkad (2001), Han et al. (2000), and Dunn (2001). This article is limited to review a few selected papers that study the effects of unsteady wake on the linear cascade blade film cooling with standard cylindrical holes and advanced shaped holes.

\section{Unsteady Effect on Turbine Blade Film Cooling}

To design an effective cooling system, it is necessary to better understand the detailed hot gas flow physics within the turbine stages. Turbine blade heat transfer and film cooling have been studied for many years. Recent studies focus on combustion generated high turbulence effect on turbine stator heat transfer with or without film cooling, upstream unsteady wake effect on downstream rotor blade heat transfer with or without film cooling, and surface roughness or thermal barrier coatings and spallations effect on blade heat transfer with or without film cooling. Recent studies also focus on providing highly detailed heat transfer coefficient and film cooling effectiveness distributions on turbine blades under unsteady high turbulence flow conditions by using the transient liquid crystal image method. One important finding from these studies is that unsteady high turbulent flows do not dramatically change heat transfer coefficient distributions on 
the film-cooled blade, but significantly reduce the film cooling effectiveness. This finding is crucial because the turbine blade might not be well protected by film cooling under the hostile turbo machinery flow environments. To optimize the film cooling performance, the effects of film hole size, length, spacing, shape, and orientation on turbine blade surface heat transfer distributions need to be considered. Results show that the shaped film-cooling hole provides better film cooling performance than the standard cylindrical film-cooling hole.

It is well known that downstream blades are affected by unsteady wakes shed by upstream vane trailing edges. Ou et al. (1994) and Mehendale et al. (1994) used the rotating spoked wheel-type wake generators to simulate the effect of unsteady wake on downstream stationary blade film cooling performance. A typical turbine blade was placed in a large-scale low speed linear 2-D turbine cascade facility. The test blade has three rows of film cooling holes on the leading edge and two rows each on the pressure and suction surfaces. Air and $\mathrm{CO}_{2}$ were used as coolants to simulate different coolant-to-mainstream density ratio effect for a range of coolant-to-mainstream blowing ratio. Du et al. (1998) used a transient liquid crystal technique to measure the detailed heat transfer coefficient and film cooling effectiveness distributions on the same film-cooled blade from the same unsteady wake simulation facility. They concluded that heat transfer coefficients for a film-cooled blade are much higher compared to a blade without film injection. In particular, film injection causes earlier boundary layer transition on the suction surface of the blade. Unsteady wakes only slightly enhance heat transfer coefficients but significantly reduce film-cooling effectiveness on a film-cooled blade compared with a film-cooled blade without unsteady wakes. This is because the heat transfer coefficients on a film cooled blade are already very high due to high turbulence and mixing caused by jet interaction with the mainstream. The additional mixing caused by unsteady wakes might not increase much on already highly disturbed flow heat transfer coefficients. However, the additional mixing caused by unsteady wakes would reduce protection of the surface by the coolant jets.

\section{Film Hole Shape Effect on Turbine Blade Film Cooling}

To improve cooling effectiveness, one solution is to contour the film-hole geometry. Film cooling holes with a diffusershaped expansion at the exit portion of the holes are believed to improve the film cooling performance on a gas turbine blade. The increased cross-sectional area at the film hole exit compared to a standard cylindrical hole leads to the reduction of the coolant jet velocity for a given blowing ratio. The momentum flux of the jet exiting the shaped hole and the penetration of the jet into the mainstream will be reduced, which results in an increased film cooling effectiveness. Furthermore, lateral expansion of the hole provides an improved lateral spreading of the jet, which leads to a better lateral film cooling coverage of the blade. A few previous studies have shown that expanding the exit of the cooling hole improves film-cooling performance compared to a standard cylindrical hole. For example, Schmidt et al. (1996) and Sen et al. (1996) compared a forward-expanded hole to a cylindrical hole, both of them having compound angle injection for the flat-plate film cooling. They found that there is a larger lateral spreading of the forward expanded hole even though the spatially averaged effectiveness is the same for both cases. Gritsch et al. (1998a, 1998b) studied detailed measurements of the flat-plate film cooling effectiveness and heat transfer coefficients downstream of a single film-cooling hole by using an IR camera method. They reported that, compared to the cylindrical hole, the two types of expanded holes in their study (the fan shaped hole and the laidback fan shaped hole) show significantly improved thermal protection of the surface downstream of the injection, particularly at the high blowing ratios.

Teng et al. (2001a, 2001b) studied the effect of film hole shape on turbine blade film cooling performance under unsteady wake flow conditions. They used the same unsteady wake simulation facility as Du et al. (1998) and focused on only one row of film holes near the suction-side gill hole region in order to investigate the hole-shape effect on the curved blade surface under strong flow acceleration conditions. Film cooling holes with and without exit expansions are tested and compared under steady and unsteady wake flow conditions. Detailed heat transfer coefficient and film cooling effectiveness distributions downstream of the injection were measured by using a transient liquid crystal image technique. They found that both fan-shaped and laidback fan-shaped holes have much lower heat transfer coefficients right after the film injection location when compared with cylindrical holes under the same unsteady wake flow conditions. They have almost the same boundary-layer transition location as the cylindrical film hole case, but their heat transfer coefficients are higher after transition into the turbulent region. In general, fanshaped holes provide better film cooling effectiveness than laidback fan-shaped holes and consequently much better film cooling effectiveness than cylindrical holes. Both fan-shaped holes and laidback fan-shaped holes provide lower span-wise averaged heat flux ratio and thus better thermal protection over the blade surface, especially under unsteady wake flow conditions.

\section{CONCLUSIONS}

Most experimental data available to date are for the main body of turbine blade external heat transfer, film cooling, and internal cooling studies. To satisfy the even higher rotor inlet temperature requirement, turbine edge region cooling becomes an important problem for the new generation of turbine blade designs. Turbine blade edge region cooling includes blade end-wall heat transfer and film cooling, blade trailing edge region heat transfer with internal coolant injection along the trailing edge base, and blade tip region heat transfer with or without film cooling under engine flow conditions. Highly accurate and highly detailed local heat transfer data in these turbine edge regions would be needed to prevent the blade edges from failure due to local hot spots. More studies are needed for the blade-shaped coolant passages 
with high performance ribs and with and without film cooling holes under realistic coolant flow, thermal, and rotation conditions. Also, more studies are needed for rotating impingement cooling with and without film coolant extraction as well as rotating pin-fin cooling with and without trailing edge ejection in order to guide the efficient rotor blade internal cooling designs. The advanced CFD predictions would provide valuable information for designing effective cooled rotor blades for the new generation of gas turbines.

\section{REFERENCES}

Abhari, R. S., and Epstein, A. H. 1994. An experimental study of film cooling in a rotating transonic turbine. ASME Journal of Turbomachinery 116:63-70.

Akella, K. V., and Han, J. C. 1998. Impingement cooling in rotating two-pass rectangular channels. AIAA Journal of Thermophysics and Heat Transfer 12(4):582-588.

Akella, K. V., and Han, J. C. 1999. Impingement cooling in rotating two-pass rectangular channels with ribbed walls. AIAA Journal of Thermophysics and Heat Transfer 13(3):364-371.

Al-Hadhrami, L., Griffith, T. S., and Han, J. C. 2002. Heat transfer in two-pass rotating rectangular channels $(\mathrm{AR}=2)$ with parallel and crossed $45^{\circ}$ V-shaped rib turbulators. AIAA Paper No. 2002-0789; ASME Journal of Heat Transfer, April 2003, 125(2).

Al-Hadhrami, L., and Han, J. C. 2002. Effect of rotation in two-pass square channels with parallel and crossed 45 angled rib turbulators. Proceeding of 9th International Symposium on Transport Phenomena and Dynamics of Rotating Machinery, ISROMAC-9, HT-ABS031; International Journal of Heat and Mass Transfer, February 2003, 46:653-669.

Al-Qahtani, M., Jang, Y. J., Chen, H. C., and Han, J. C. 2001. Prediction of flow and heat transfer in rotating two-pass rectangular channels with 45-degree rib turbulators. ASME Paper No. 2001-GT-187; ASME Journal of Turbomachinery, April 2002, 124:242-250.

Azad, G. S., Uddin, J. M., Han, J. C., Moon, H. K., and Glezer, B. 2001. Heat transfer in a two-pass rectangular rotating channel with 45-degree angled rib turbulators. ASME Paper No. 2001-GT-186; ASME Journal of Turbomachinery, April 2002, 124:251-259.

Bonhoff, B., Tomm, U., Johnson, B. V., and Jennions, I. 1997. Heat transfer predictions for rotating U-shaped coolant channels with skewed ribs and smooth walls. ASME Paper No. 97-GT-162.

Camci, C., and Arts, T. 1985. Short-duration measurements and numerical simulation of heat transfer along the suction side of a gas turbine blade. ASME Journal of Engineering for Gas Turbines and Power 107:991-997.

Du, H., Han, J. C., and Ekkad, S. V. 1998. Effect of unsteady wake on detailed heat transfer coefficient and film effectiveness distributions for a gas turbine blade. ASME Journal of Turbomachinery 120:808817.

Dunn, M. G. 2001. Convection heat transfer and aerodynamics in axial flow turbines. ASME Journal of Turbomachinery 123(4):637-686.

Dutta, S., and Han, J. C. 1996. Local heat transfer in rotating smooth and ribbed two-pass square channels with three channel orientations. ASME Journal of Heat Transfer 118(3):578-584.

Dutta, S., and Han, J. C. 1998. Rotational effect on the turbine blade coolant passage heat transfer. Annual Review of Heat Transfer IX:269-314.
Dutta, S., Han, J. C., and Lee, C. P. 1996a. Local heat transfer in a rotating two-pass ribbed triangular duct with two model orientations. International Journal of Heat and Mass Transfer 39(4):707-715.

Dutta, S., Han, J. C., Zhang, Y. M., and Lee, C. P. 1996b. Local heat transfer in a rotating two-pass triangular duct with smooth walls. ASME Journal of Turbomachinery 118(3):435-443.

Ekkad, S. V., Huang, Y., and Han, J. C. 1998. Detailed heat transfer distributions in two-pass smooth and turbulated square channels with bleed holes. International Journal of Heat and Mass Transfer 41(13):3781-3791.

Epstein, A. H., Kerrebrock, J. L., Koo, J. J., and Preiser, U. Z. 1985. Rotational effects on impingement cooling. M.I.T. Gas Turbine Laboratory Report No. 184.

Glezer, B., Moon, H. K., Kerrebrock, J., Bons, J., and Guenette, G. 1998. Heat transfer in a rotating radial channel with swirling internal flow. ASME Paper No. 98-GT-214.

Goldstein, R. J. 2001. Heat transfer in gas turbine systems. New York. Annals of The New York Academy of Sciences 934.

Griffith, T. S., Al-Hadhrami, L., and Han, J. C. 2001. Heat transfer in rotating rectangular cooling channels $(\mathrm{AR}=4)$ with angled ribs. AIAA Paper No. 2001-2820; ASME Journal of Heat Transfer, August 2002, 124(4):617-625.

Gritsch, M., Schulz, A., and Wittig, S. 1998a. Adiabatic wall effectiveness measurements of film cooling holes with expanded exits. ASME Journal of Turbomachinery 120:549-556.

Gritsch, M., Schulz, A., and Wittig, S. 1998b. Heat transfer coefficient measurements of film cooling holes with expanded exits. ASME Paper No. 98-GT-28.

Han, J. C. 1988. Heat transfer and friction characteristics in rectangular channels with rib turbulators. ASME Journal of Heat Transfer 110(2):321-328.

Han, J. C., and Dutta, S. 2001. Recent developments in turbine blade internal cooling, in Heat Transfer in Gas Turbine Systems, edited by Richard J. Goldstein, Annals of the New York Academy of Sciences 934:162-178.

Han, J. C., Dutta, S., and Ekkad, S. V. 2000. Gas turbine heat transfer and cooling technology, New York, Taylor \& Francis, Inc.

Han, J. C., and Ekkad, S. V. 2001. "Recent developments in turbine blade film cooling. International Journal of Rotating Machinery 7(1):21-40.

Han, J. C., Glicksman, L. R., and Rohsenow, W. M. 1978. An investigation of heat transfer and friction for rib-roughened surfaces. International Journal of Heat and Mass Transfer 21:1143-1156.

Han, J. C., Huang, J. J., and Lee, C. P. 1993. Augmented heat transfer in square channels with wedge-shaped and delta-shaped turbulence promoters. Journal of Enhanced Heat Transfer 1(1):37-52.

Han, J. C., Ou, S., Park, J. S., and Lei, C. K. 1989. Augmented heat transfer in rectangular channels of narrow aspect ratios with rib turbulators. International Journal of Heat and Mass Transfer 32(9):16191630.

Han, J. C., and Park, J. S. 1988. Developing heat transfer in rectangular channels with rib turbulators. International Journal of Heat and Mass Transfer 31(1):183-195.

Han, J. C., Park, J. S., and Lei, C. K. 1985. Heat transfer enhancement in channels with turbulence promoters. ASME Journal of Engineering for Gas Turbines and Power 107(1):628-635.

Han, J. C., and Zhang, P. 1991. Effect of rib angle orientation on local mass transfer distribution in a three-pass rib-roughened channel. ASME Journal of Turbomachinery 113:123-130. 
Han, J. C., and Zhang, Y. M. 1992. High performance heat transfer ducts with parallel and V-shaped broken ribs. International Journal of Heat and Mass Transfer 35(2):513-523.

Han, J. C., Zhang, Y. M., and Kalkuehler, K. 1993. Uneven wall temperature effect on local heat transfer in a rotating two-pass square channel with smooth walls. ASME Journal of Heat Transfer 114(4):850 858.

Harasgama, S. P., and Burton, C. D. 1992. Film cooling research on the endwall of a turbine nozzle guide vane in a short-duration annular cascade. Part I: Experimental technique and results. ASME Journal of Turbomachinery 114:734-740.

Iacovides, H., and Raisee, M. 1999. Recent progress in the computation of flow and heat transfer in internal cooling passages of turbine blades. International Journal of Heat and Fluid Flow 20:320-328.

Jang, Y. J., Chen, H. C., and Han, J. C. 2001. Flow and heat transfer in a rotating square channel with 45 -degree angled ribs by reynolds stress turbulence model. ASME Journal of Turbomachinery 123(1):124132.

Johnson, B. V., Wagner, J. H., Steuber, G. D., and Yeh, F. C. 1994a. Heat transfer in rotating serpentine passages with selected model orientations for smooth or skewed tip walls. ASME Journal of Turbomachinery 116:738-744.

Johnson, B. V., Wagner, J. H., Steuber, G. D., and Yeh, F. C. 1994b. Heat transfer in rotating serpentine passages with trips skewed to the flow. ASME Journal of Turbomachinery 116(1):113-123.

Kim, Y. W., Downs, J. P., Soechting, F. O., Abdel-Messeh, W., Steuber, G. D., and Tanrikut, S. 1995. A summary of the cooled turbine blade tip heat transfer and film effectiveness investigations performed by Dr. D. E. Metzger. ASME Journal of Turbomachinery 117:1-11.

Mattern, C., and Hennecke, D. K. 1996. The influence of rotation on impingement cooling, ASME Paper No. 96-GT-161.

Mehendale, A. B., and Han, J. C. 1992. Influence of high mainstream turbulence on leading edge film cooling heat transfer. ASME Journal of Turbomachinery 114:707-715.

Mehendale, A. B., Han, J. C., Ou, S., and Lee, C. P. 1994. Unsteady wake over a linear turbine blade cascade with air and $\mathrm{CO}_{2}$ film injection: Part II: Effect on film effectiveness and heat transfer distributions. ASME Journal of Turbomachinery 116:730-737.

Nirmalan, N. V., and Hylton, L. D. 1990. An experimental study of turbine vane heat transfer with leading edge and downstream film cooling. ASME Journal of Turbomachinery 112:477-487.

Ou, S., Han J. C., Mehendale, A. B., and Lee, C. P. 1994. Unsteady wake over a linear turbine blade cascade with air and $\mathrm{CO}_{2}$ film injection: Part I: Effect on heat transfer coefficients. ASME Journal of Turbomachinery 116:721-729.

Parsons, J. A., Han, J. C., and Lee, C. P. 1998. Rotation effect on jet impingement heat transfer in smooth rectangular channels with heated target walls and radially outward crossflow. International Journal of Heat and Mass Transfer 41(13):2059-2071.
Parsons, J. A., Han, J. C., and Zhang, Y. M. 1994. Wall heating effect on local heat transfer in a rotating two-pass square channel with 90-degree rib turbulators. International Journal of Heat and Mass Transfer 37(9):1411-1420.

Parsons, J. A., Han, J. C., and Zhang, Y. M.. 1995. Effects of model orientation and wall heating condition on local heat transfer in a rotating two-pass square channel with rib turbulators. International Journal of Heat and Mass Transfer 38(7):1151-1159.

Rathjen, L., Hennecke, D. K., Bock, S., and Kleinstuck, R. 2001. Detailed heat/mass transfer distributions in a rotating two pass coolant channel with engine-near cross section and smooth walls, in Heat Transfer in Gas Turbine Systems, edited by Richard J., Goldstein, Annals of The New York Academy of Sciences 934:432439.

Schmidt, D. L., Sen, B., and Bogard, D. G. 1996. Film cooling with compound angle holes: adiabatic effectiveness. ASME Journal of Turbomachinery 118:807-813.

Sen, B., Schmidt, D. L., and Bogard, D. G. 1996. Film cooling with compound angle holes: heat transfer. ASME Journal of Turbomachinery 118:800-806.

Stephens, M. A., Chyu, M. K., and Shih, T. I.-P. 1997. Computation of compressible flow and heat transfer in a rotating duct with inclined ribs and a 180-deg bend, ASME Paper No. 97-GT-192.

Taslim, M. E., and Lengkong, A. 1998a. 45-degree round-corner rib heat transfer coefficient measurements in a square channel. ASME Paper No. 98-GT-176.

Taslim, M. E., and Lengkong, A. 1998b. 45-degree staggered rib heat transfer coefficient measurements in a square channel. ASME Journal of Turbomachinery 120(3):571-580.

Taslim, M. E., and Wadsworth, C. M. 1997. An experimental investigation of the rib surface-averaged heat transfer coefficient in a rib-roughened square passage. ASME Journal of Turbomachinery 119:381-389.

Teng, S., Han, J. C., and Poinsatte, P. E. 2001a. Effect of film-hole shape on turbine-blade film-cooling performance. AIAA Journal of Thermophysics and Heat Transfer 15(3):257-265.

Teng, S., Han, J. C., and Poinsatte, P. E. 2001b. Effect of film-hole shape on turbine-blade heat-transfer coefficient distribution. AIAA Journal of Thermophysics and Heat Transfer 15(3):249-256.

Wagner, J. H., Johnson, B. V., and Kopper, F. C. 1991. Heat transfer in rotating serpentine passages with smooth walls. ASME Journal of Turbomachinery 113:321-330.

Willett, F. T., and Bergles, A. E. 2000. Heat transfer in rotating narrow rectangular ducts with heated sides oriented at 60 -degree to the R-Z plane. ASME Paper No. 2000-GT-224.

Zhang, Y. M., Han, J. C., Parsons, J. A., and Lee, C. P. 1995. Surface heating effect on local heat transfer in a rotating two-pass square channel with 60-degree angled rib turbulators. ASME Journal of Turbomachinery 117(2):272-278. 

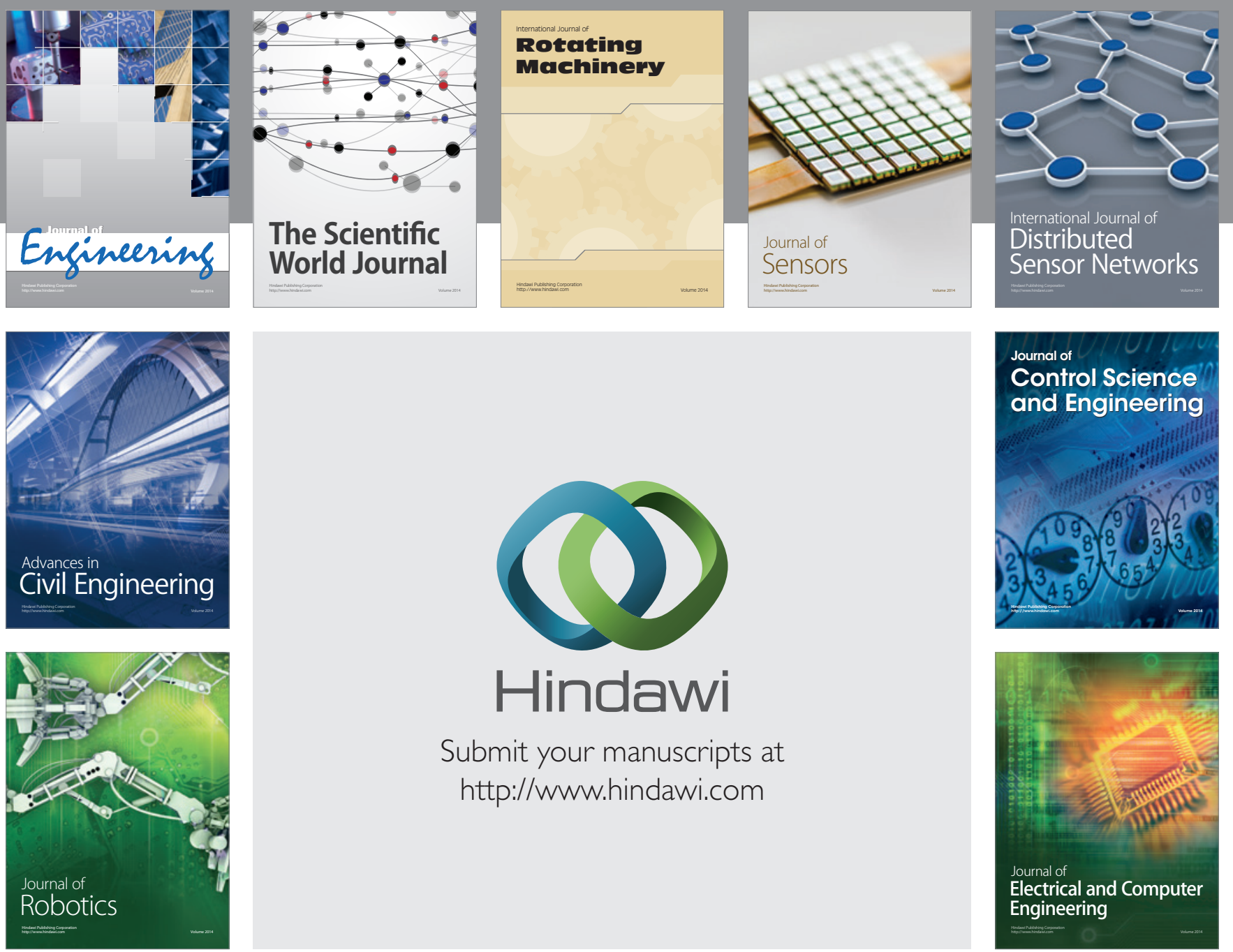

Submit your manuscripts at

http://www.hindawi.com
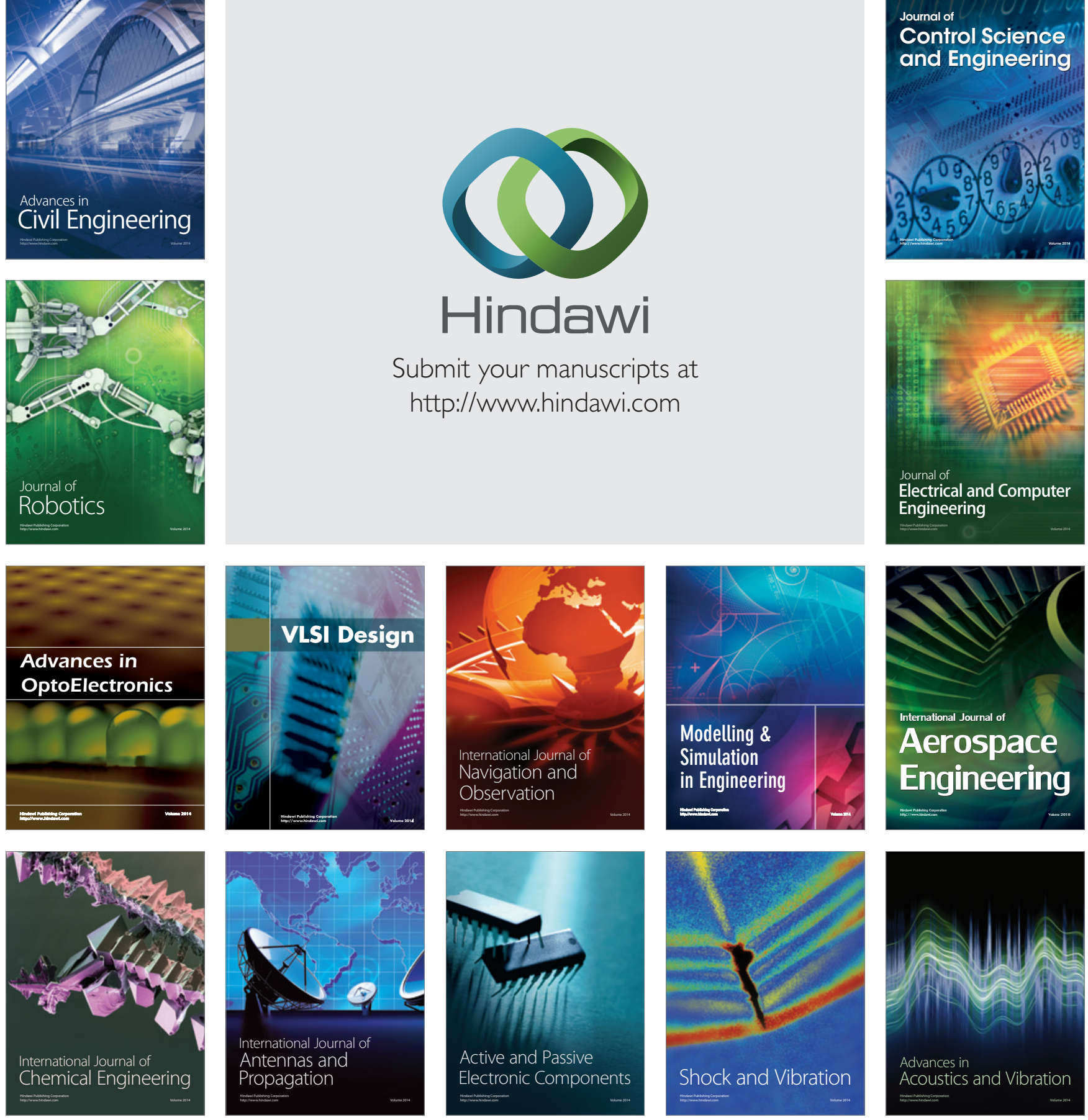